\title{
Aberrant, differential and bidirectional regulation of the unfolded protein response towards cell survival by 3'-deoxyadenosine
}

\author{
M Kitamura ${ }^{1}$, H Kato ${ }^{1}$, Y Saito ${ }^{1}$, S Nakajima ${ }^{1}$, S Takahashi ${ }^{1}$, H Johno ${ }^{1}$, L Gu${ }^{1}$ and R Katoh ${ }^{2}$
}

The unfolded protein response (UPR) is involved in a diverse range of pathologies triggered by endoplasmic reticulum (ER) stress. Endeavor to seek selective regulators of the UPR is a promising challenge towards therapeutic intervention in ER stressrelated disorders. In the present report, we describe aberrant, differential and bidirectional regulation of the UPR by $3^{\prime}$-deoxyadenosine (cordycepin) towards cell survival. $3^{\prime}$-Deoxyadenosine blocked ER stress-induced apoptosis via inhibiting the IRE1-JNK pro-apoptotic pathway. $3^{\prime}$-Deoxyadenosine also inhibited apoptosis through reinforcement of the pro-survival elF2 $\alpha$ signaling without affecting PERK activity. It was associated with depression of GADD34 that dephosphorylates elF2 $\alpha$, and dephosphorylation of elF $2 \alpha$ by salubrinal mimicked the anti-apoptotic effect of $3^{\prime}$-deoxyadenosine. Unexpectedly, although $3^{\prime}$-deoxyadenosine caused activation of elF2 $\alpha$, it inhibited downstream pro-apoptotic events including induction of ATF4 and expression of CHOP. Cooperation of adenosine transporter and A3 adenosine receptor, but not A1/A2 receptors, mediated the pluripotent effects of $3^{\prime}$-deoxyadenosine. In mice, ER stress caused activation of JNK, expression of CHOP and induction of apoptosis in renal tubules. The apoptosis was significantly attenuated by administration with $3^{\prime}$-deoxyadenosine, and it was correlated with blunted induction of JNK and CHOP in the kidney. These results disclosed atypical pro-survival regulation of the UPR by $3^{\prime}$-deoxyadenosine, which may be advantageous for the treatment of intractable, ER stress-related disorders.

Cell Death and Differentiation (2011) 18, 1876-1888; doi:10.1038/cdd.2011.63; published online 20 May 2011

Endoplasmic reticulum (ER) stress-mediated tissue injury is implicated in a wide range of pathologies including cancers, infection, atherosclerosis, ischemia, neurodegenerative disorders and metabolic diseases such as diabetes mellitus. ${ }^{1}$ Seeking selective regulators for the unfolded protein response (UPR) is a promising challenge towards control of ER stress and ER stress-related disorders. To date, however, little is known about biological substances that allow for selective manipulation of individual UPR pathways.

A number of pathophysiological insults lead to accumulation of unfolded proteins in the ER, that is, ER stress. Three major transducers for ER stress are located on the membrane of the ER; activating transcription factor 6 (ATF6), inositol-requiring enzyme 1 (IRE1) and PKR-like ER kinase (PERK), all of which contribute to attenuation of stress conditions. ${ }^{2}$ In response to ER stress, p90ATF6 transits to the Golgi where it is cleaved by the proteases $\mathrm{S} 1 \mathrm{P}$ and $\mathrm{S} 2 \mathrm{P}$, yielding a free cytoplasmic domain (p50ATF6) that functions as a transcription factor. Similarly, activated IRE1 catalyzes removal of a small intron from X-box- binding protein 1 (XBP1) mRNA. This splicing event creates a translational frameshift in $X B P 1$ to produce an active transcription factor. p50ATF6 and XBP1 subsequently bind to the ER stress response element (ERSE) and the UPR element (UPRE), leading to expression of target genes including (i) ER chaperones such as $78 \mathrm{kDa}$ glucose-regulated protein (GRP78), GRP94 and $150 \mathrm{kDa}$ oxygen-regulated protein (ORP150), and (ii) ER-associated degradation (ERAD) factors such as ER degradation enhancing $\alpha$-mannosidase-like protein 1 (Edem1). Activation of PERK leads to phosphorylation of eukaryotic translation initiation factor $2 \alpha$ (elF2 $\alpha$ ), which causes general inhibition of protein synthesis. This molecular event contributes to attenuation of ER stress, and salubrinal, an inhibitor of elF2 $\alpha$ dephosphorylation, is considered as a potential therapeutic agent for the treatment of ER stressrelated pathologies including viral infection. ${ }^{3,4}$

During the UPR, however, death signals, as well as survival signals, may also be transduced via PERK and IRE $1 .{ }^{5}$ For example, the PERK-elF2 $\alpha$ pathway induces expression of

\footnotetext{
${ }^{1}$ Department of Molecular Signaling, Interdisciplinary Graduate School of Medicine and Engineering, University of Yamanashi, Chuo, Yamanashi 409-3898, Japan and ${ }^{2}$ Department Pathology, Interdisciplinary Graduate School of Medicine and Engineering, University of Yamanashi, Chuo, Yamanashi 409-3898, Japan Corresponding author: Professor M Kitamura, Department of Molecular Signaling, Interdisciplinary Graduate School of Medicine and Engineering, University of Yamanashi, Shimokato 1110, Chuo, Yamanashi 409-3898, Japan. Tel/Fax: + 81-55-273-8054; E-mail: masanori@yamanashi.ac.jp

Keywords: 3 '-deoxyadenosine; cordycepin; unfolded protein response; apoptosis; IRE1; elF2 $\alpha$

Abbreviations: ER, endoplasmic reticulum; UPR, unfolded protein response; ATF6, activating transcription factor 6; IRE1, inositol-requiring enzyme 1; PERK, PKR-like ER kinase; XBP1, X-box-binding protein 1; ERSE, ER stress response element; UPRE, UPR element; GRP78, $78 \mathrm{kDa}$ glucose-regulated protein; ORP150, $150 \mathrm{kDa}$ oxygen-regulated protein; ERAD, ER-associated degradation; Edem1, ER degradation enhancing $\alpha$-mannosidase-like protein 1; elF2 $\alpha$, eukaryotic translation initiation factor $2 \alpha$; CHOP, CCAAT/enhancer-binding protein-homologous protein; GADD34, growth arrest and DNA damage gene 34; ASK1, apoptosis signal-regulating kinase 1; JNK, c-Jun N-terminal kinase; DTT, dithiothreitol; SubAB, subtilase cytotoxin; DPSPX, 1,3-dipropyl-8-(p-sulfophenyl)xanthine; NBTI, S-(4-nitrobenzyl)-6-thioinosine; SEAP, secreted alkaline phosphatase; SV40, simian virus 40; GAPDH, glyceraldehyde-3-phosphate dehydrogenase; EF- $1 \alpha$, elongation factor-1 $\alpha$; CMV, cytomegalovirus; TUNEL, terminal deoxynucleotidyl transferase-mediated dUTP-biotin nick end labeling; FBS, fetal bovine serum; DAPI, 4'-6-diamidino-2-phenylindole; XBP1(U), unspliced form of $X B P 1 ; \mathrm{XBP} 1(\mathrm{~S})$, spliced form of $X B P 1$

Received 14.12.10; revised 14.4.11; accepted 14.4.11; Edited by G Kroemer; published online 20.5.11
} 
pro-apoptotic CCAAT/enhancer-binding protein-homologous protein (CHOP) through the ATF4-the amino acid response element pathway. ${ }^{6}$ The PERK-elF2 $\alpha-$ ATF4 pathway also induces expression of another pro-apoptotic molecule, growth arrest and DNA damage gene 34 (GADD34). ${ }^{7}$ On the other hand, activation of IRE1 results in recruitment and activation of apoptosis signal-regulating kinase 1 (ASK1) and downstream c-Jun N-terminal kinase (JNK), both of which are involved in a wide range of pro-apoptotic processes. ${ }^{8}$ These signaling pathways offset the effects of the pro-survival UPR. Based on this current concept, development of agents that selectively reinforce the pro-survival UPR but suppress the pro-apoptotic UPR is an important challenge towards effective treatments for ER stress-related diseases.

3'-Deoxyadenosine, also called cordycepin, has been identified as a major bioactive metabolite in Cordyceps militaris. ${ }^{8,9}$ It possesses a wide range of biological effects including antithrombotic, anti-cancer, anti-viral, anti-fungal and anti-inflammatory activities. In mice, administration of $3^{\prime}$-deoxyadenosine reduces tumor formation in a model of metastasis ${ }^{10}$ and has been proposed as an anti-cancer drug. The anti-cancer activity of $3^{\prime}$-deoxyadenosine is, in part, ascribed to its anti-mitogenic effect $^{10,11}$, but many recent studies suggested that induction of apoptosis is one of major mechanisms involved in the potential of $3^{\prime}$-deoxyadenosine against malignant tumors. ${ }^{12-15}$ In contrast, anti-apoptotic properties of this agent have not been reported to date. Recently, we occasionally found that $3^{\prime}$-deoxyadenosine has the potential to modulate the UPR against ER stress-induced cell injury. In the present report, we provide evidence for aberrant, pro-survival regulation of the UPR by $3^{\prime}$-deoxyadenosine.

\section{Results}

Selective suppression of ER stress-induced apoptosis by $3^{\prime}$-deoxyadenosine. Previous reports suggested that induction of apoptosis is one of major mechanisms underlying the anti-tumorigenic potential of $3^{\prime}$-deoxyadenosine at high concentrations. ${ }^{12-15}$ However, we occasionally found that nontoxic doses of $3^{\prime}$-deoxyadenosine $(\sim 5 \mu \mathrm{g} / \mathrm{ml})$ suppress apoptosis triggered by ER stress. When NRK-52E rat renal tubular cells were treated with tunicamycin, cytoplasmic vacuolation was induced (Figure 1a, top middle). Further incubation caused shrinkage of the cytoplasm and membrane blebbing typical of apoptosis (Figure 1a, bottom middle). Concomitant treatment with $3^{\prime}$-deoxyadenosine suppressed these morphological changes (Figure 1a, right). Quantitative analysis showed that cellular death triggered by tunicamycin was significantly suppressed by $3^{\prime}$-deoxyadenosine (Figure 1b). The cell damage was reversed by $3^{\prime}$-deoxyadenosine in a dosedependent manner (Figures $1 \mathrm{c}$ and $\mathrm{d}$ ). The pro-survival effect was similarly observed in cells treated with thapsigargin, a different inducer of ER stress (Figures 1e and f). Hoechst staining (Sigma-Aldrich Japan, Tokyo, Japan) showed that nuclear fragmentation caused by tunicamycin or thapsigargin was suppressed by $3^{\prime}$-deoxyadenosine (Figures $1 \mathrm{~g}$ and $\mathrm{h}$ ), confirming inhibition of apoptotic cell death. Western blot analysis also exhibited that activation of caspase-3 was blocked by the treatment with $3^{\prime}$-deoxyadenosine (Figure 1i).
The similar cytoprotective effect was observed in other cell types including human lung epithelial cells BEAS-2B (Supplementary Figures S1A and S1B).

We examined selectivity of the anti-apoptotic potential of 3 '-deoxyadenosine. Under TNF- $\alpha$-stimulated condition, 3 '-deoxyadenosine markedly enhanced TNF- $\alpha$-induced cell injury (Figures $1 \mathrm{j}$ and k). Similarly, treatment with $3^{\prime}$-deoxyadenosine promoted cellular damage caused by cadmium and cigarette smoke extract (Figure 1j). Staurosporine-induced cellular damage was unaffected by $3^{\prime}$-deoxyadenosine. In contrast, like tunicamycin- and thapsigargin-induced apoptosis, cellular death triggered by other ER stress inducers (dithiothreitol (DTT) and subtilase cytotoxin (SubAB)) was suppressed by $3^{\prime}$-deoxyadenosine (Figures $1 \mathrm{j}$ and $\mathrm{I}$ ). Of note, even after the full induction of the UPR, post-treatment with $3^{\prime}$-deoxyadenosine similarly suppressed morphological damage (Supplementary Figure S2A) and cellular death (Supplementary Figure S2B).

Involvement of extracellular and intracellular actions in anti-apoptotic effect of $\mathbf{3}^{\prime}$-deoxyadenosine. Extracellular adenosine and adenine nucleotides control a variety of cell function. ${ }^{16-18}$ Microscopic analysis showed that, in contrast to 3'-deoxyadenosine, ATP, ADP and adenosine did not inhibit thapsigargin-induced cell injury (Figure 2a). Quantitative analysis confirmed that ER stress-induced cellular death was not affected by the treatment with these adenosine-related substances (Figure 2b).

A previous report suggested that $3^{\prime}$-deoxyadenosine inhibits growth of tumor cells through binding to the A3 adenosine receptor. ${ }^{10}$ We tested an effect of $A 3$ receptor antagonist, MRS1523, on the pro-survival action of 3 -deoxyadenosine. As shown in Figures $2 \mathrm{c}-\mathrm{f}$, the antiapoptotic effect of $3^{\prime}$-deoxyadenosine was abolished in the presence of MRS1523. In contrast, treatment with $A 1 / A 2$ receptor antagonist 1,3-dipropyl-8-(p-sulfophenyl)xanthine (DPSPX) did not reverse the effect of $3^{\prime}$-deoxyadenosine even at high concentrations (Supplementary Figures S3A and S3B).

Adenosine and other adenine nucleosides are transported across the cell membrane via adenosine transporters. To investigate whether intracellular action also contributes to the pro-survival effect of 3 -deoxyadenosine, we tested an effect of adenosine transport inhibitor S-(4-nitrobenzyl)-6-thioinosine (NBTI). As shown in Figures $2 g-j$, the anti-apoptotic effect of $3^{\prime}$-deoxyadenosine was inhibited by NBTI. Treatment with NBTI alone did not induce any cellular injury.

Effects of $3^{\prime}$-deoxyadenosine on the expression of endogenous ER stress markers. To elucidate whether or not 3'-deoxyadenosine attenuates ER stress, its effects on the induction of endogenous ER stress markers were examined. Northern blot analysis revealed that $3^{\prime}$-deoxyadenosine markedly suppressed induction of CHOP and GRP78 in a dose-dependent manner (Figure 3a). Similar suppressive effects were observed on the expression of other ER stress markers, GRP94 and ORP150 (Figure 3b). The suppressive effect of $3^{\prime}$-deoxyadenosine was also observed in cells exposed to SubAB, a more selective inducer of ER stress ${ }^{19}$ (Figure $3 \mathrm{c}$ ). This phenomenon was observed in different cell types including rat mesangial cells (Figures $3 d$ and e) and mouse 
3T3-L1 preadipocytes (our unpublished data). Consistent with the results shown in Supplementary Figures S2A and S2B, post-treatment with $3^{\prime}$-deoxyadenosine similarly downregulated the levels of CHOP and GRP78 mRNAs (Supplementary Figure S4). The reduction in $C H O P$ and GRP78 was caused by transcriptional suppression, because degradation rate of these mRNAs was not influenced by $3^{\prime}$-deoxyadenosine (Figure 3f). Of note, $3^{\prime}$-deoxyadenosine did not affect expression levels of secreted alkaline phosphatase (SEAP) driven by the simian virus 40 (SV40) promoter (Supplementary Figure S5). Expression levels of endogenous housekeeping genes elongation factor-1 $\alpha(E F-1 \alpha)$ and glyceraldehyde-3-phosphate dehydrogenase (GAPDH) were not suppressed by 3'-deoxyadenosine (Supplementary Figure S6).
In contrast to $3^{\prime}$-deoxyadenosine, ATP, ADP and adenosine did not suppress the expression of CHOP and GRP78 triggered by ER stress inducers (Figure $3 \mathrm{~g}$ ). Consistent with the results shown in Figure 2c-f, MRS1523 partially reversed the suppressive effects of $3^{\prime}$-deoxyadenosine on $\mathrm{CHOP}$ and GRP78 (Figure 3h). DPSPX did not affect the effect of 3 -deoxyadenosine (Figure 3i). Furthermore, the suppressive effects of $3^{\prime}$-deoxyadenosine on CHOP and GRP78 were also reversed partially by $\mathrm{NBTI}$ (Figure $3 \mathrm{j}$ ). When cells were co-treated with MRS1523 and NBTI, the inhibitory effect of 3 -deoxyadenosine was abrogated (Figure $3 \mathrm{k}$ ).

Suppression of the IRE1 pathway by $3^{\prime}$-deoxyadenosine. ER stress causes the UPR that involves

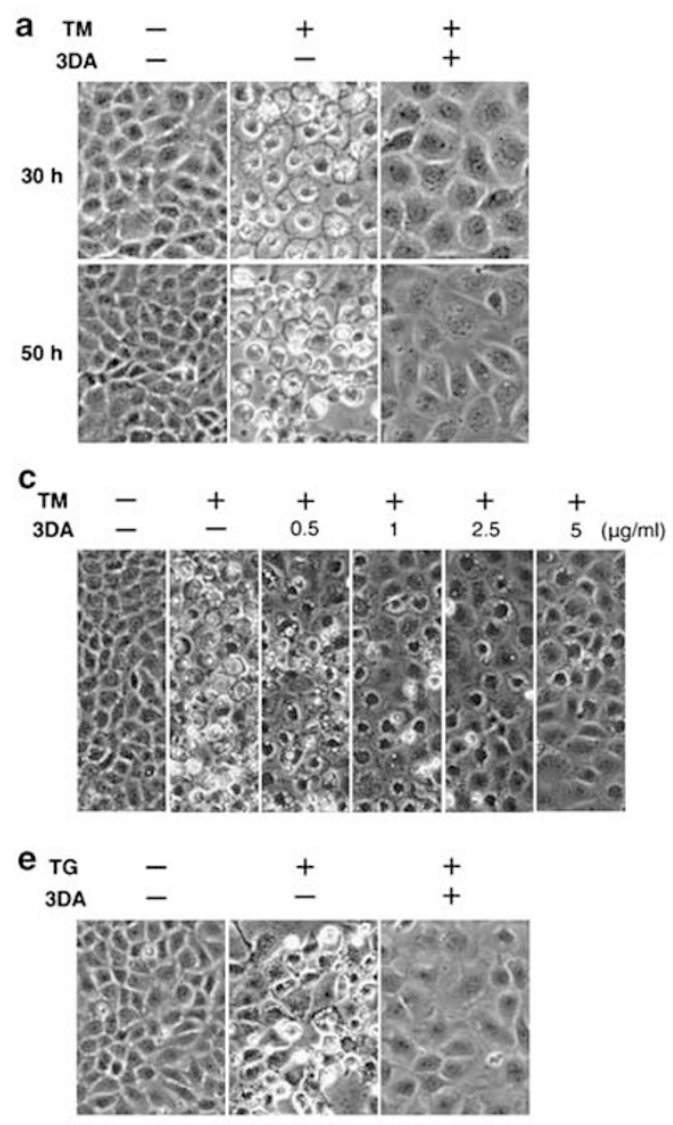

b
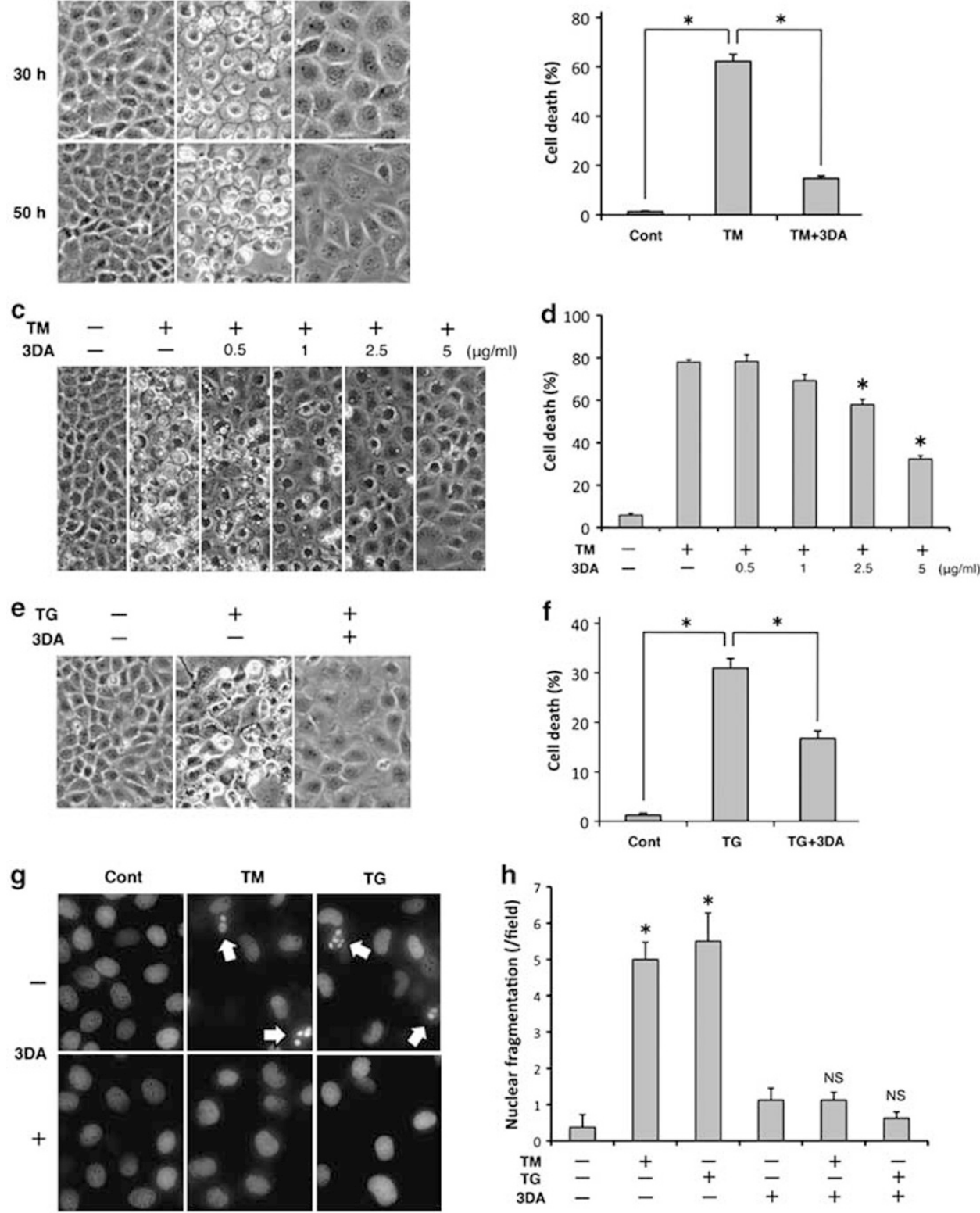

Figure 1 (Continued) 


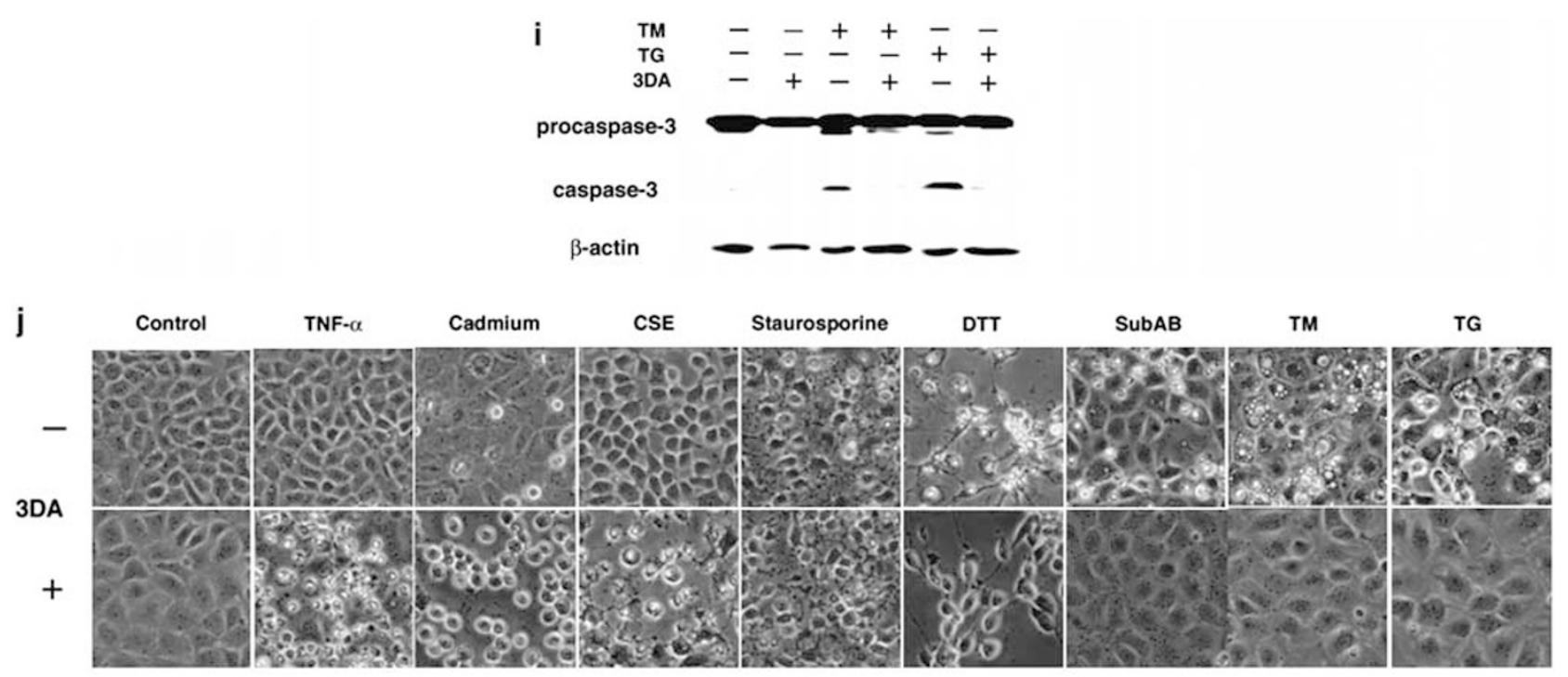

k

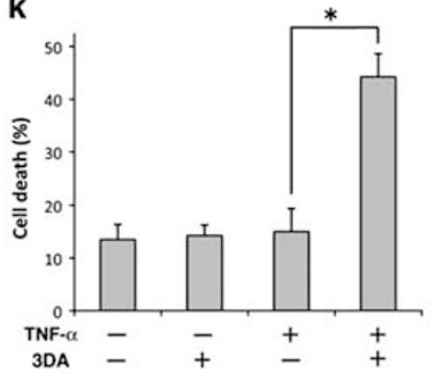

।

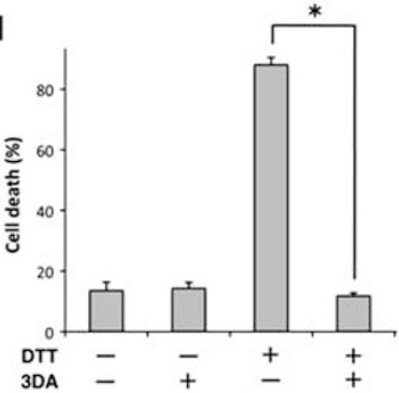

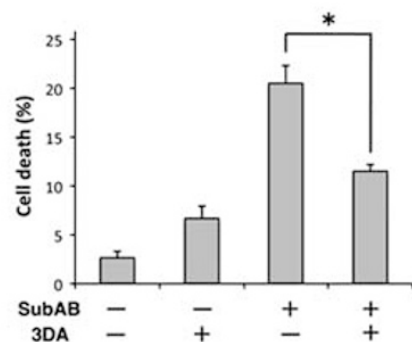

Figure 1 Suppression of ER stress-induced apoptosis by $3^{\prime}$-deoxyadenosine. NRK-52E cells were treated with $2.5 \mu \mathrm{g} / \mathrm{ml}$ tunicamycin (TM) (a-d) or $500 \mathrm{nM}$ thapsigargin (TG) (e and f) in the absence $(-)$ or presence $(+)$ of $3^{\prime}$-deoxyadenosine (3DA; $\left.5 \mu \mathrm{g} / \mathrm{ml}\right)$ and subjected to phase-contrast microscopy (a, $\mathbf{c}$ and $\left.\mathbf{e}\right)$. Both attached cells and detached cells were harvested separately and subjected to trypan blue analysis. The percentages of dead cells against total cells were evaluated (b, $\mathbf{d}$ and $\mathbf{f})$. Assays were performed in quadruplicate, and data are presented as means \pm S.E. Asterisks indicate statistically significant differences $(P<0.05)$. ( $(\mathbf{g}$ and $\mathbf{h})$ Cells were exposed to TM or TG with or without 3DA and subjected to Hoechst staining. (g) fluorescent microscopy. Nuclear fragmentation is indicated by arrows. Cont, untreated control. (h) quantitative analysis of nuclear fragmentation. NS, not statistically significant. (i) Cells were treated with TM, TG and 3DA as indicated, and western blot analysis was performed to evaluate activation of caspase-3. The level of $\beta$-actin is shown at the bottom as a loading control. (j-I) NRK-52E cells were exposed to pro-apoptotic stimuli $(10 \mathrm{ng} / \mathrm{ml} \mathrm{TNF-} \alpha, 20 \mu \mathrm{M}$ cadmium, $5 \%$ cigarette smoke extract (CSE), $200 \mathrm{nM}$ staurosporine, $2 \mathrm{mM} \mathrm{DTT}, 50 \mathrm{ng} / \mathrm{ml}$ subtilase cytotoxin (SubAB), TM and TG) in the absence or presence of 3DA and subjected to phase-contrast microscopy (j) and assessment of cell death ( $\mathbf{k}$ and $\mathbf{I}$ )

activation of IRE1, ATF6 and PERK-elF2 $\alpha$ pathways. We first examined effects of $3^{\prime}$-deoxyadenosine on the activation of the IRE1 pathway. Splicing of XBP1 mRNA was used as an indicator for IRE1 activation. As shown in Figure 4a, thapsigargin induced splicing of XBP1 time-dependently, which was suppressed by the treatment with $3^{\prime}$-deoxyadenosine. Consistently, RT-PCR analysis showed that splicing of endogenous XBP1 mRNA caused by tunicamycin and thapsigargin was inhibited by $3^{\prime}$-deoxyadenosine (Figure $4 \mathrm{~b}$ ). The suppression of IRE1 was further confirmed by blunted activation of UPRE and ERSE (Figures $4 \mathrm{c}$ and d). This inhibitory effect was not due to non-specific effects on the reporter system, because luciferase activity driven by the EF- $1 \alpha$ promoter and the cytomegalovirus (CMV) promoter/enhancer was not depressed by $3^{\prime}$-deoxyadenosine (Supplementary Figure S7). Similarly, induction of Edem1, a molecule downstream of the IRE1-XBP1 pathway, ${ }^{20}$ was inhibited by $3^{\prime}$-deoxyadenosine (Figure $4 \mathrm{e}$ ). Phosphorylation of JNK, another downstream indicator for IRE1 activation, was also suppressed by the treatment with $3^{\prime}$-deoxyadenosine (Figure 4f).
ERSE is activated not only by XBP1 but also by ATF6. Activation of the ATF6-ERSE pathway is the major mechanism underlying the induction of ER chaperones by ER stress. ${ }^{21}$ Our data showed that $3^{\prime}$-deoxyadenosine suppressed ER stress-induced activation of ERSE and induction of GRP78, GRP94 and ORP150 (Figures 3a-e, 4d). These results indicate a possibility that the ATF6 pathway is also blocked by $3^{\prime}$-deoxyadenosine.

Consistent with the results of northern blot analysis, MRS1523 modestly and NBTI substantially reversed the suppressive effects of $3^{\prime}$-deoxyadenosine on the splicing of $X B P 1 \mathrm{mRNA}$ and activation of UPRE and ERSE (Figures $4 \mathrm{~g}-\mathrm{i}$ ). In contrast, treatment with DPSPX had no impacts on the effects of $3^{\prime}$-deoxyadenosine.

Atypical regulation of the PERK-elF2 $\alpha$ pathway by 3 '-deoxyadenosine. We further examined effects of $3^{\prime}$-deoxyadenosine on the activation of the PERK-elF2 $\alpha$ pathway by ER stress. Western blot analysis showed that, unexpectedly, treatment with $3^{\prime}$-deoxyadenosine did not 
a

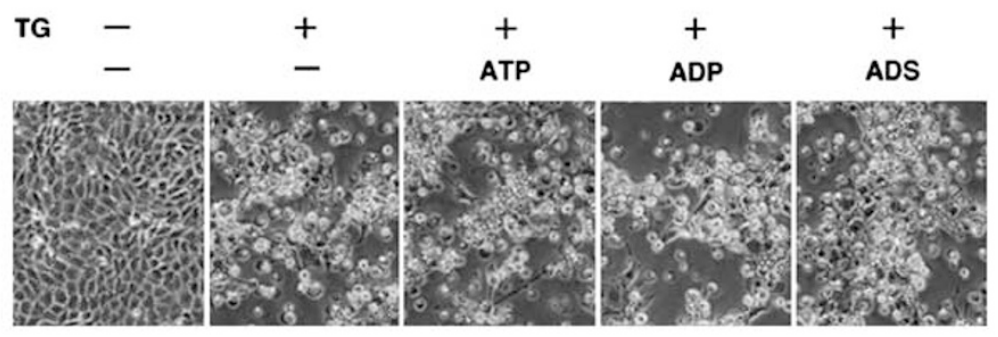

C

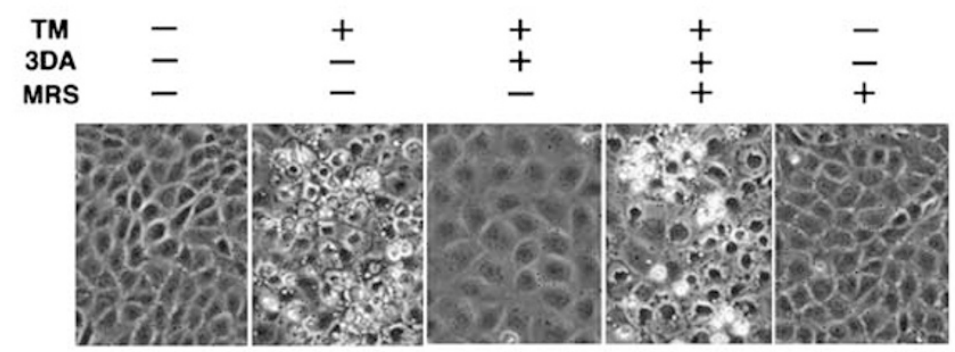

e

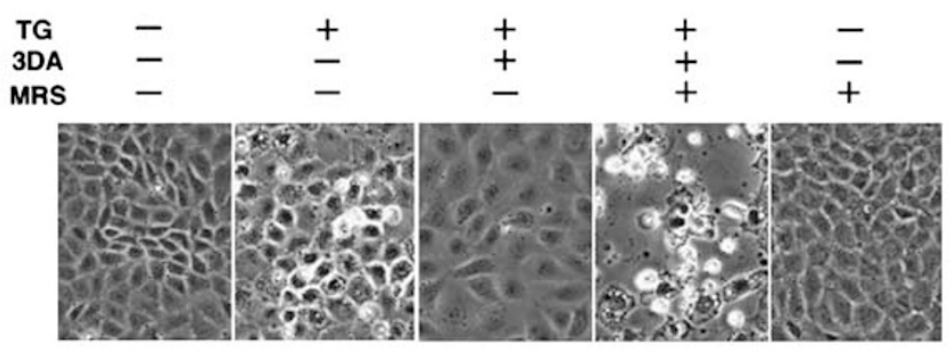

g

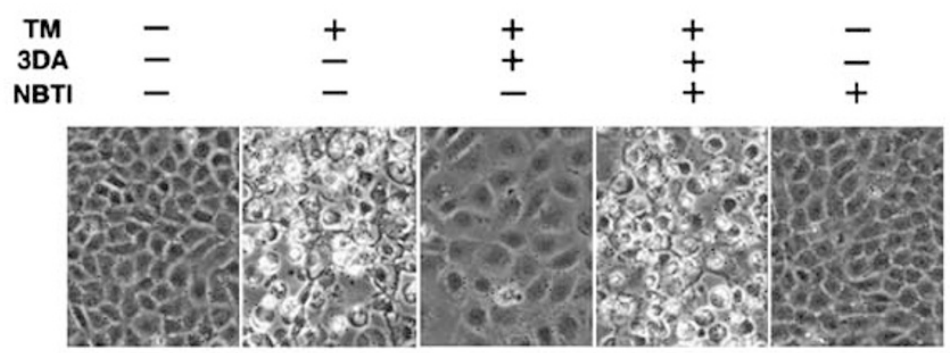

i

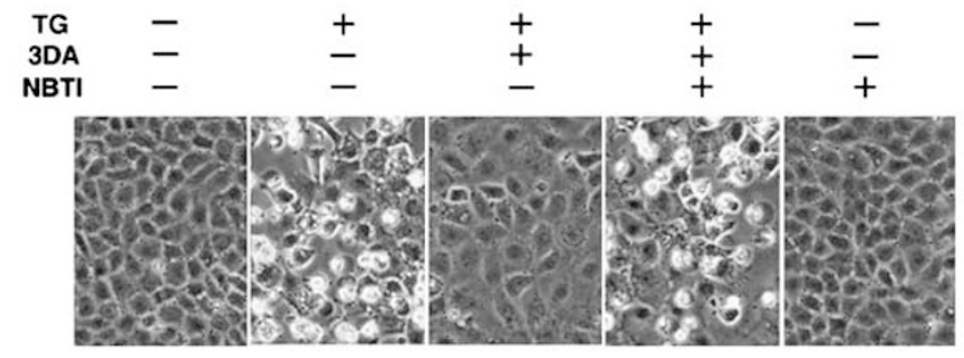

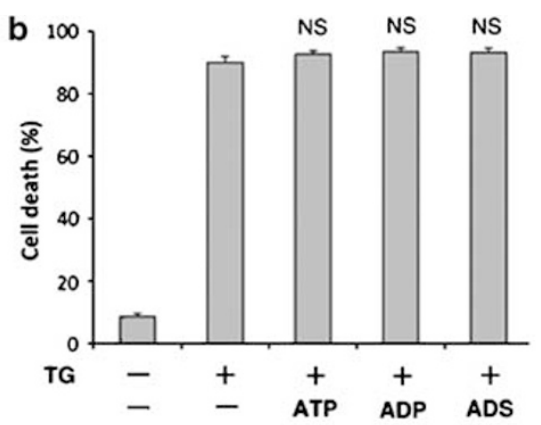

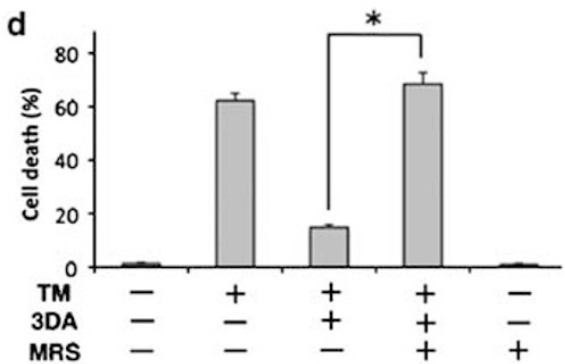

f

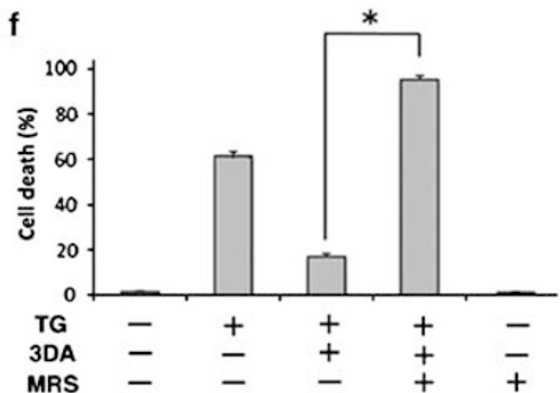

h
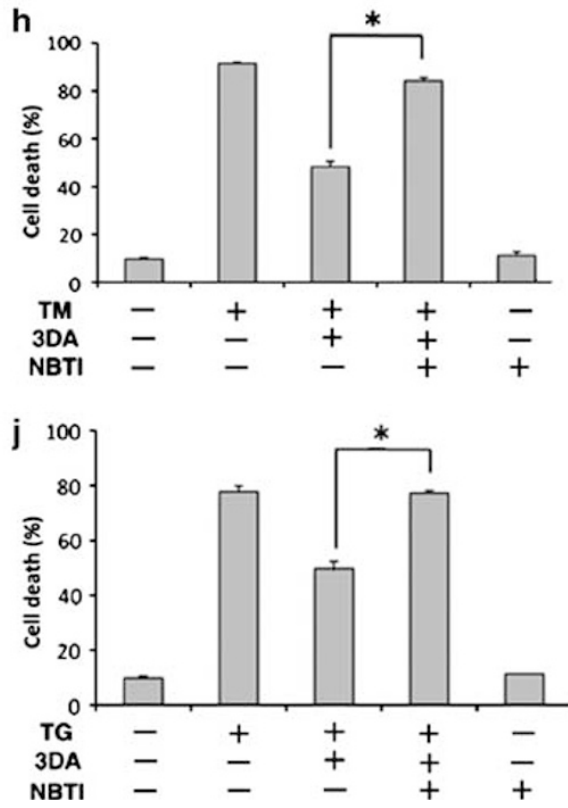

Figure 2 Involvement of extracellular and intracellular actions in the anti-apoptotic effect of $3^{\prime}$-deoxyadenosine. (a and $\mathbf{b}$ ) NRK-52E cells were exposed to TG in the presence of ATP, ADP or adenosine (ADS) at $100 \mu \mathrm{M}$ and subjected to phase-contrast microscopy (a) and assessment of cell death (b). (c-f) Cell were treated with TM, TG and 3DA in the absence or presence of $5 \mu \mathrm{M}$ MRS1523 (MRS), and subjected to phase-contrast microscopy (c and $\mathbf{e}$ ) and assessment of cell death (d and f). (g-j) Cells were exposed to TM or TG with or without $10 \mu \mathrm{M} \mathrm{NBTI}$ and subjected to phase-contrast microscopy (g and $\mathbf{i})$ and cell death analysis (h and $\mathbf{j}) .{ }^{*} P<0.05$ 


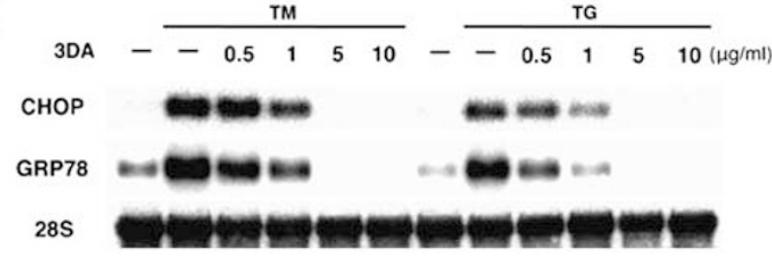

b

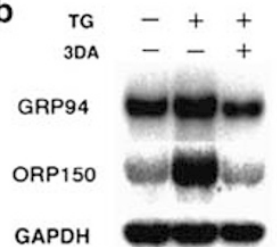

C

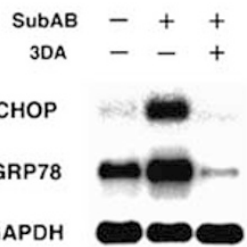

d $\begin{aligned} & -\mathrm{TM} \text { TM } \\ \text { 3DA } & -\mathrm{TG} \text { TG }\end{aligned}$ CHOP

GRP78

GAPDH

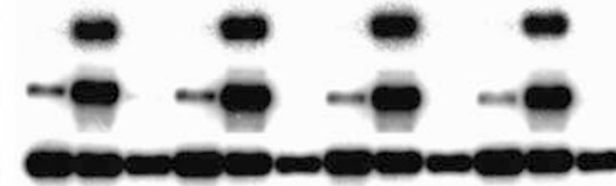

e

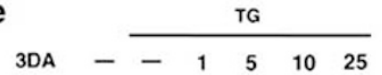

SubAB

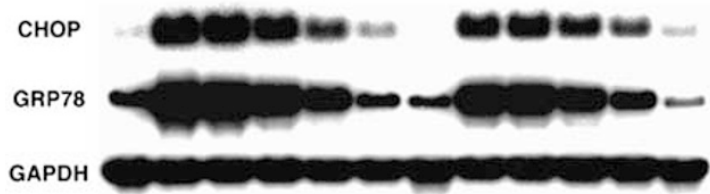

f
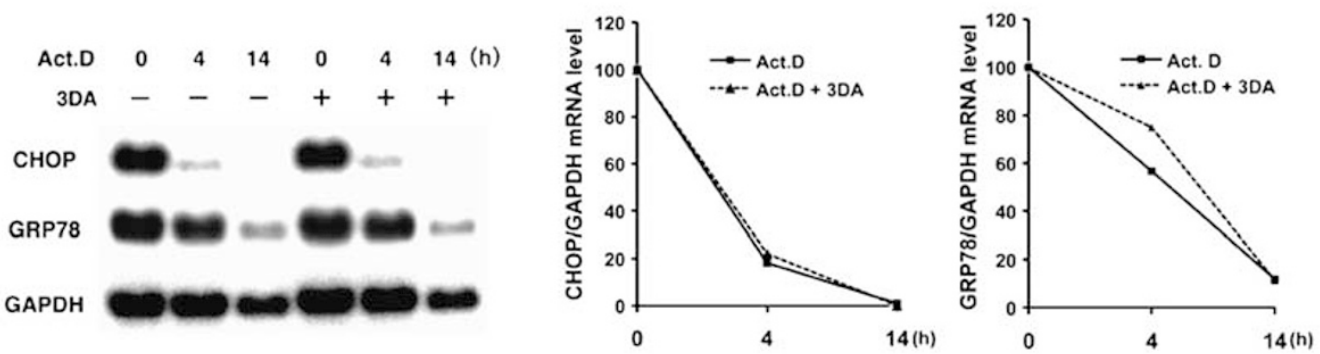

g

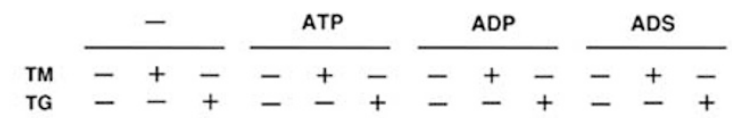

h $3 \mathrm{DA}--++++++--$ MRS $----\infty-++++$

- TM TG - TM TG - TM TG - TM TG
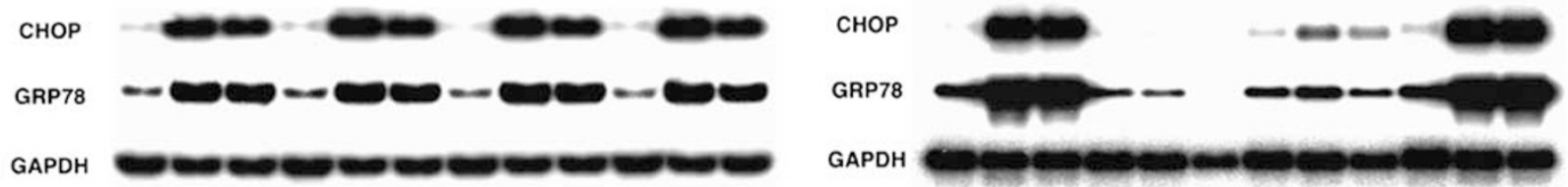

i

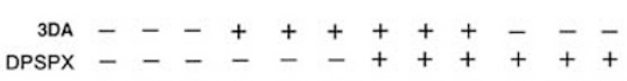
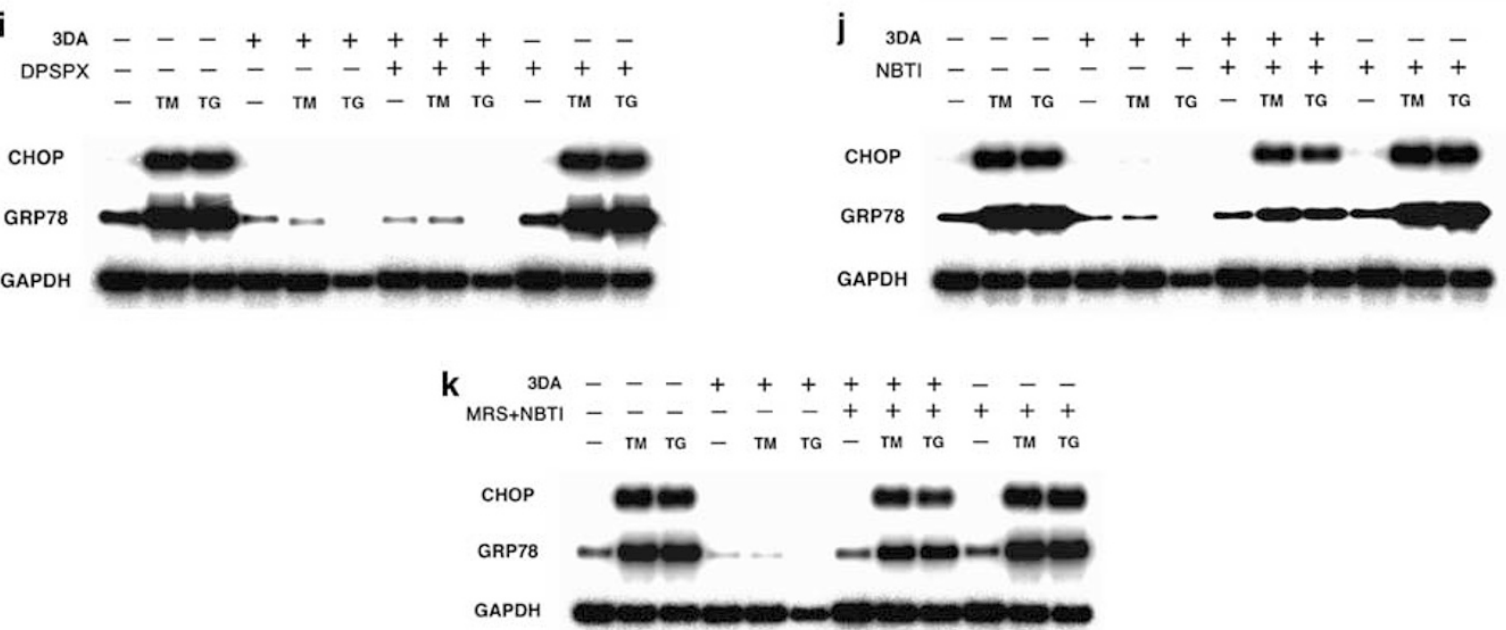

Figure 3 Effects of $3^{\prime}$-deoxyadenosine on the induction of ER stress markers. (a-c) NRK-52E cells were stimulated for $8 \mathrm{~h}$ with TM or TG (a and $\left.\mathbf{b}\right)$ or $25 \mathrm{ng} / \mathrm{ml}$ SubAB (c) in the presence of 3DA, and expression of CHOP and GRP78 (a and c) and GRP94 and ORP150 (b) was evaluated by northern blot analysis. Levels of $28 \mathrm{~S}$ ribosomal RNA and GAPDH are shown at the bottom as loading controls. (a and e) SM43 mesangial cells were exposed to various inducers of ER stress (TM, TG, $500 \mathrm{nM}$ A23187 (A23), SubAB) in the presence of $100 \mu \mathrm{g} / \mathrm{ml} \mathrm{3DA}$ (d) or its serial concentrations (e), and induction of CHOP and GRP78 was assessed. (f) Cells were treated with $5 \mu \mathrm{g} / \mathrm{ml}$ actinomycin $\mathrm{D}($ Act.D) in the absence or presence of $3 \mathrm{DA}$ for 4 and $14 \mathrm{~h}$, and northern blot analysis was performed. The levels of CHOP and GRP78 were normalized by the level of GAPDH, and relative levels of CHOP and GRP78 mRNAs are shown in graphs. (g) Cells were exposed to TM or TG for $8 \mathrm{~h}$ in the absence or presence of ATP, ADP or ADS, and northern blot analysis was performed. (h-k) Cell were treated with TM, TG and 3DA in the presence of MRS (h), $10 \mathrm{nM}$ DPSPX (i), NBTI (j) or MRS + NBTI (k) and subjected to northern blot analysis 

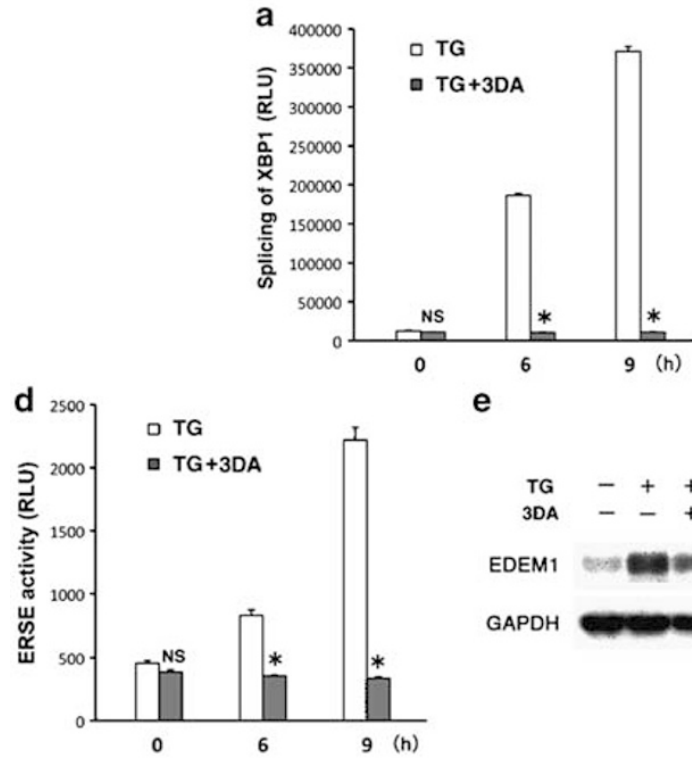

e

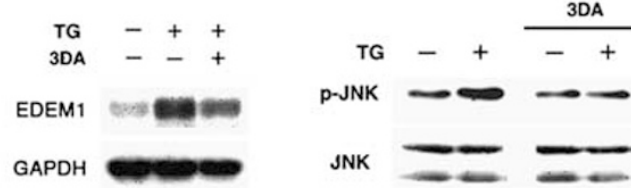

b

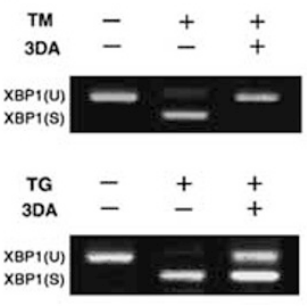

c

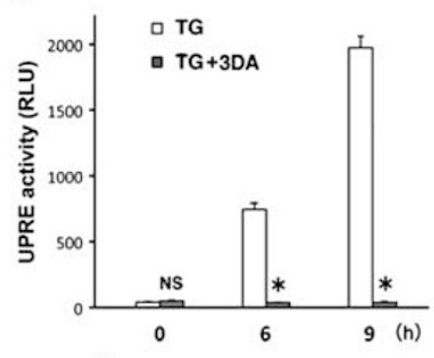

g
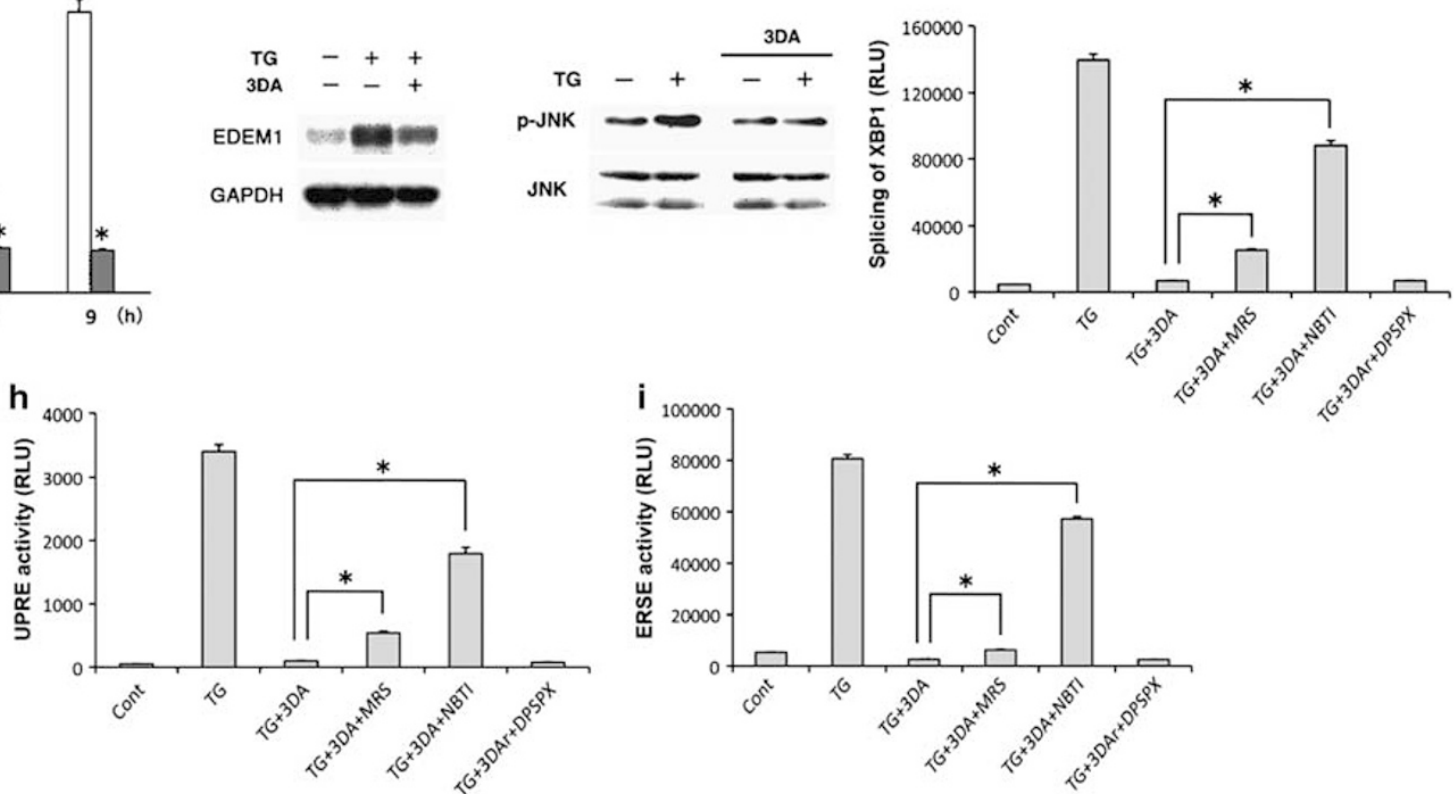

Figure 4 Suppression of the IRE1 pathway by $3^{\prime}$-deoxyadenosine. (a, $\mathbf{c}$ and d) NRK-52E cells transiently transfected with a XBP1 reporter plasmid (a), NRK/UPRE-Luc cells (c) and NRK/ERSE-Luc cells (d) were treated with TG for $6 \mathrm{~h}$ and $9 \mathrm{~h}$ in the absence or presence of 3DA and subjected to chemiluminescent assay. RLU, relative light unit. (b) Cells were treated with TM or TG for $4 \mathrm{~h}$ and subjected to RT-PCR analysis of XBP1 mRNA. XBP1(U), unspliced form of XBP1; XBP1(S), spliced form of XBP1. (e) Cells were stimulated for $8 \mathrm{~h}$ with TG in the absence or presence of 3DA, and expression of Edem1 was evaluated by northern blot analysis. (f) Cells were stimulated with TG for $15 \mathrm{~min}$ in the absence or presence of 3DA, and phosphorylation of JNK (p-JNK) was evaluated by western blot analysis. Total JNK protein is shown as a loading control. (g-i) NRK-52E cells transiently transfected with the XBP1 reporter plasmid (g), NRK/UPRE-Luc cells (h) and NRK/ERSE-Luc cells (i) were treated with indicated agents for $12 \mathrm{~h}$ and subjected to chemiluminescent assay. ${ }^{*} P<0.05$

suppress the early phosphorylation of PERK by ER stress (Figure 5a). Furthermore, 3'-deoxyadenosine induced substantial phosphorylation of elF $2 \alpha$ and rather enhanced thapsigargin-triggered elF2 $\alpha$ phosphorylation (Figure $5 b$ ).

We examined roles of adenosine transporters and adenosine receptors in the phosphorylation of elF2 $\alpha$. Western blot analysis showed that treatment with NBTI, but not MRS1523 and DPSPX, suppressed activation of elF2 $\alpha$ by $3^{\prime}$-deoxyadenosine (Figure $5 \mathrm{c}$ ). The lack of involvement of the adenosine A3 receptor was further confirmed by a time-lapse experiment (Figure 5d). However, in the later phase (12-24h), blockade of the A3 receptor reduced the phosphorylation level of elF2 $\alpha$ (Figure 5e). This phenomenon was also observed when cells were treated with $3^{\prime}$-deoxyadenosine together with thapsigargin (Figure $5 f$ ).

GADD34 forms a functional complex with protein phosphatase 1 and causes dephosphorylation of elF $2 \alpha^{7,22}$ To identify molecular events involved in the sustained phosphorylation of elF2 $\alpha$ by $3^{\prime}$-deoxyadenosine, expression of GADD34 was evaluated. Northern blot analysis showed that $3^{\prime}$-deoxyade- nosine did not induce GADD34 and rather suppressed induction of $G A D D 34$ by ER stress (Figure $5 \mathrm{~g}$ ). Consistent with its regulation for GRP78 and $C H O P$, suppression of $G A D D 34$ required the $A 3$ receptor and adenosine transporters, but not A1/A2 receptors (Figures $5 \mathrm{~h}-\mathrm{j}$ ). Concomitant blockade of the $A 3$ receptor and adenosine transporters completely reversed the suppressive effect of $3^{\prime}$-deoxyadenosine (Figure 5k). It is worthwhile to note that basal expression of GADD34 was detectable in unstimulated cells, and it was suppressed by $3^{\prime}$-deoxyadenosine.

To examine whether the enhanced phosphorylation of elF2 $\alpha$ is responsible for the pro-survival effect of $3^{\prime}$-deoxyadenosine, cells were exposed to thapsigargin in the absence or presence of salubrinal, a selective blocker of elF2 $\alpha$ dephosphorylation. ${ }^{3}$ Treatment with salubrinal caused rapid phosphorylation of elF2 $\alpha$ (Supplementary Figure S8), and like 3'-deoxyadenosine, salubrinal substantially suppressed ER stress-induced apoptosis (Figures $6 a$ and b). The pro-survival property of elF2 $\alpha$ signaling was further confirmed using cells stably transfected with a dominant-negative mutant of PERK (Supplementary 
a

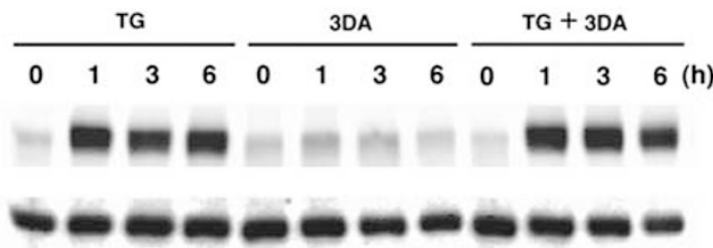

b

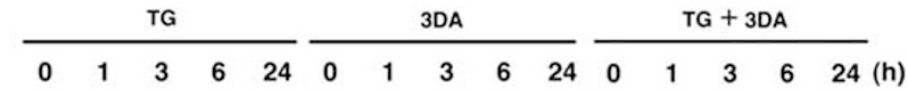

p-eIF $2 \alpha$

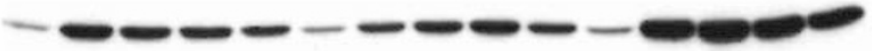

elF2 $\alpha$

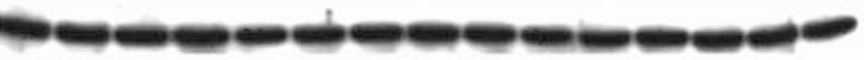

C

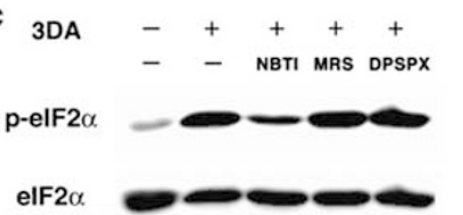

d

3DA

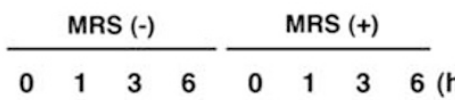

p-elF2 $\alpha=-m=-m$

elF $2 \alpha$

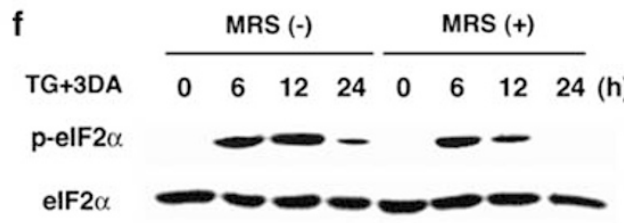

g

GADD34

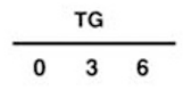

$\frac{\mathrm{TG}+3 \mathrm{DA}}{0 \quad 36}$

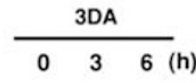

GAPDH

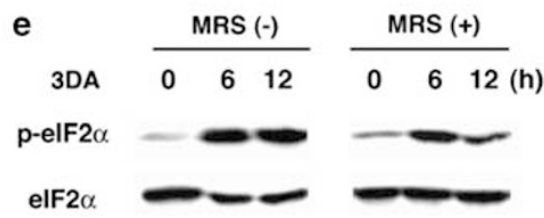

h

\begin{tabular}{|c|c|c|c|c|c|c|c|c|c|c|c|}
\hline 3DA & - & - & - & + & + & + & + & + & + & - & - \\
\hline MRS & - & - & - & - & - & - & + & + & + & + & + \\
\hline & - & TM & TG & - & TM & TG & - & $\mathrm{TM}$ & TG & - & TM \\
\hline
\end{tabular}

GADD34

GAPDH

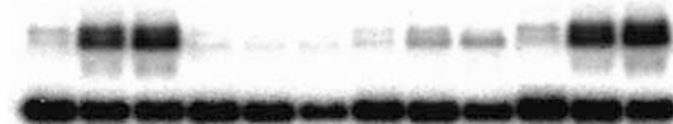

i

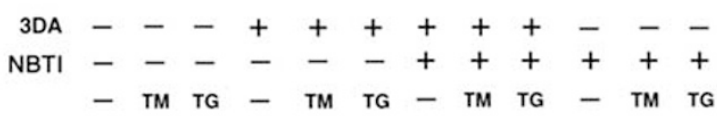

GADD34

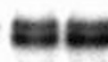

GAPDH

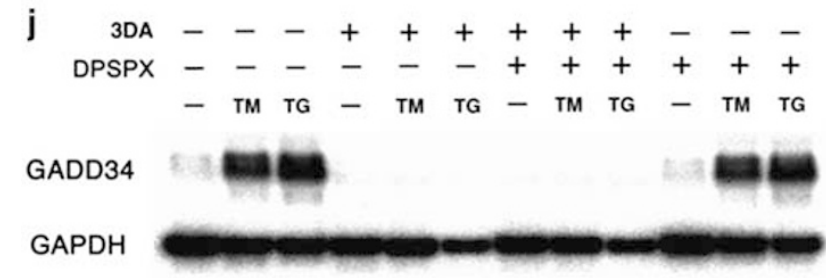

k 3DA ---++++++-MRS+NBTI $--\infty---+++++$ - TM TG - TM TG - TM TG - TM TG

GADD34

GAPDH

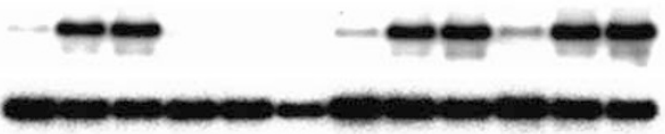

Figure 5 Atypical pro-survival regulation of the PERK-elF2 $\alpha$ pathway by $3^{\prime}$-deoxyadenosine. (a and $\mathbf{b}$ ) NRK-52E cells were treated with TG, 3DA or TG $+3 D A$ for indicated time periods and subjected to western blot analysis of phosphorylated PERK (a) and phosphorylated elF2 $\alpha$ (b). Total proteins of PERK and elF2 $\alpha$ are shown at the bottom as loading controls. (c) Cells were treated with 3DA in the presence of NBTI, MRS or DPSPX for $6 \mathrm{~h}$, and phosphorylation of elF2 $\alpha$ was evaluated. (d-f) Cells were treated with 3DA (d and $\mathbf{e}$ ) or TG $+3 D A(f)$ for indicated time periods in the absence or presence of MRS and subjected to western blot analysis. (g) Cell were treated with TG, TG + 3DA or 3DA alone for $3-6 \mathrm{~h}$ and subjected to northern blot analysis of GADD34. (h-k) Cells were treated with indicated agents for $8 \mathrm{~h}$ and subjected to northern blot analysis. ${ }^{*} P<0.05$

Figures S9A, S9B and S9C). When these cells were exposed to tunicamycin and thapsigargin, apoptosis was significantly enhanced when compared with mock-transfected cells (Figures $6 c$ and d). It was associated with increased activation of caspase-3 (Figure 6e).

In general, activation of elF2 $\alpha$ causes induction of $C H O P$ via upregulation of ATF4. ${ }^{23}$ The induction of ATF4 may be regulated at both transcriptional and translational levels. ${ }^{24,25}$ However, treatment with $3^{\prime}$-deoxyadenosine did not trigger substantial expression of CHOP and ATF4, and rather suppressed induction of these genes by ER stress (Figures $6 f$ and $g$ ). The suppressive effect of 3 '-deoxyadenosine on ATF4 was also confirmed by western blot analysis of nuclear ATF4 (Figure 6h). This effect was contrastive to salubrinal that induced expression of CHOP and ATF4, and did not suppress induction of these pro-apoptotic genes by ER stress inducers (Figure 6i). 


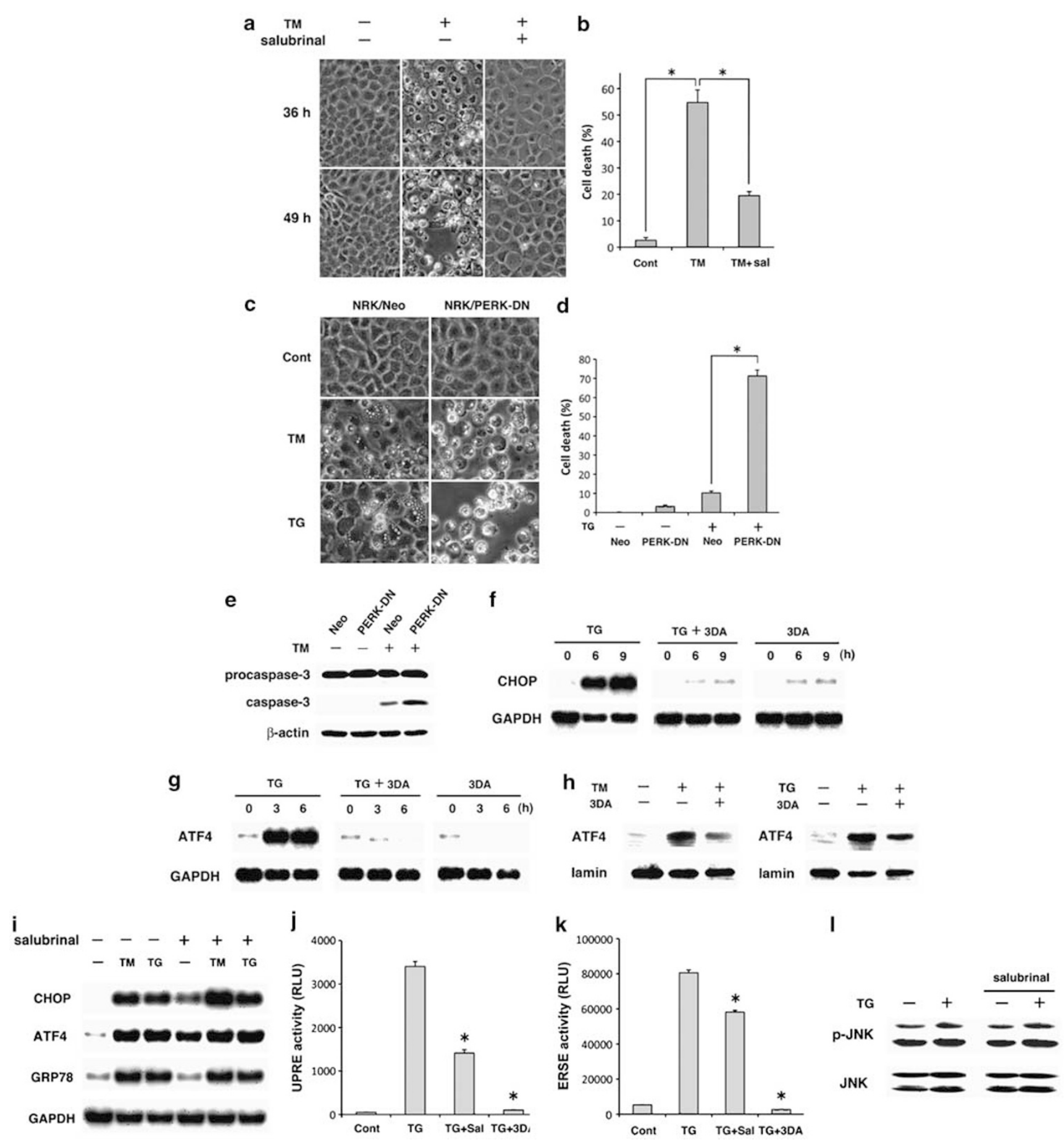

Figure 6 Suppression of apoptosis by $3^{\prime}$-deoxyadenosine through activation of elF2 $\alpha$ without induction of the ATF4-CHOP pathway. (a and $\mathbf{b}$ ) NRK-52E cells were exposed to TM in the presence of $50 \mu \mathrm{M}$ salubrinal (sal) and subjected to phase-contrast microscopy (a) and assessment of cell death (b). (c-e) NRK/Neo cells and NRK/ PERK-DN cells were treated with TM or TG and subjected to phase-contrast microscopy (c), assessment of cell death (d) and evaluation of caspase-3 activation (e). ( $\mathbf{f}$ and $\mathbf{g}$ ) NRK-52E cells were treated with TG, TG $+3 \mathrm{DA}$ or 3DA alone for indicated time periods and subjected to northern blot analysis of CHOP (f) and ATF4 (g). (h) Cells were treated with TG for 6-12 $\mathrm{h}$ in the absence or presence of 3DA, and nuclear protein was subjected to western blot analysis of ATF4. The level of lamin B1 is shown at the bottom as a loading control. (i) Cells were treated with TM or TG in the absence or presence of salubrinal, and expression of CHOP, ATF4 and GRP78 was examined. (j and $\mathbf{k}$ ) NRK/ UPRE-Luc cells (j) and NRK/ERSE-Luc cells (k) were treated with TG in the absence or presence of salubrinal or 3DA for $12 \mathrm{~h}$ and subjected to luciferase assay. (I) Cells were stimulated with TG in the absence or presence of salubrinal, and phosphorylation of JNK was evaluated by western blot analysis. ${ }^{*} P<0.05$

We examined a link between the elF2 $\alpha$ pathway and the IRE1 pathway in $3^{\prime}$-deoxyadenosine-treated cells. As shown in Figures $6 \mathrm{j}$ and $\mathrm{k}$, activation of elF $2 \alpha$ by salubrinal partially suppressed induction of the IRE1 pathway by ER stress. It was contrastive to strong suppression of UPRE and ERSE activation by $3^{\prime}$-deoxyadenosine. These results indicate that 

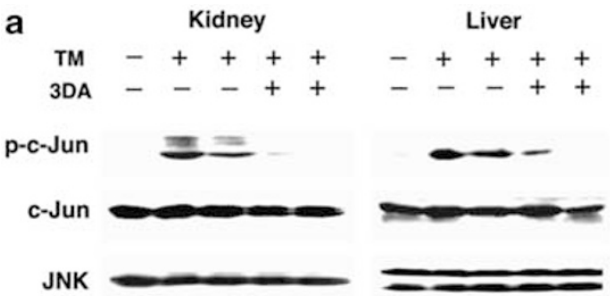

b

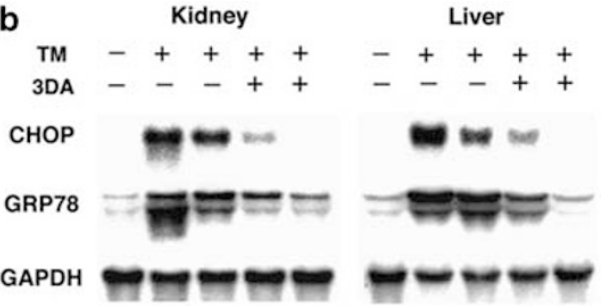

C
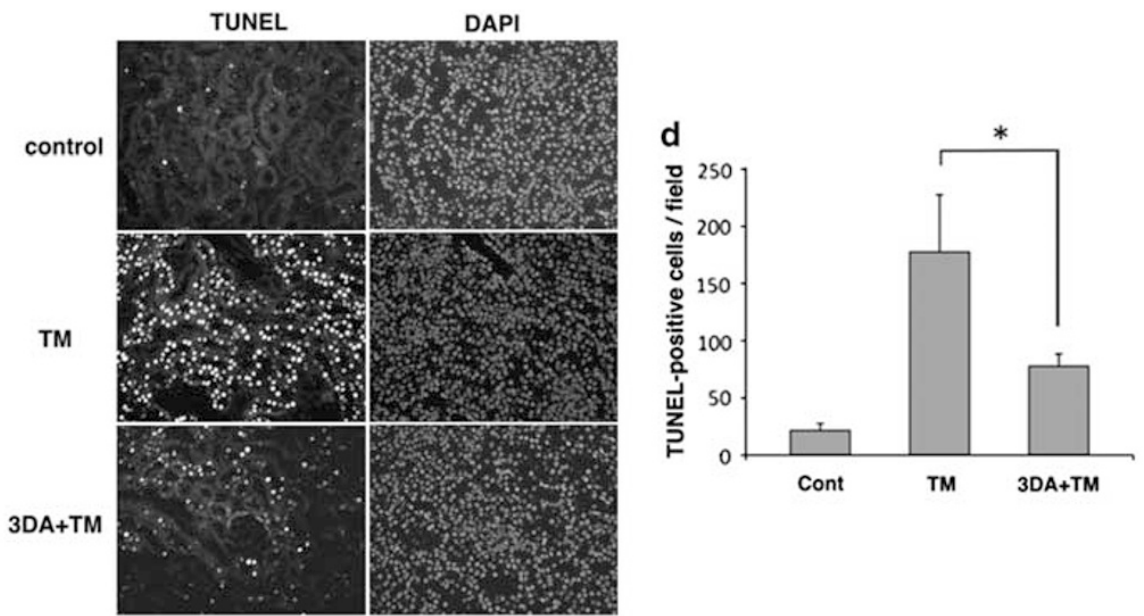

Figure 7 In vivo suppression of ER stress-induced apoptosis by 3'-deoxyadenosine. Mice were injected with PBS or 3DA (3 mg/kg) intraperitoneally on day $1,2,3$ and 4 . On day 2, mice were administered with TM (1.5 mg/kg). After 3 days (day 5), kidneys (and livers) were sampled and subjected to western blot analysis of phosphorylated c-Jun, total c-Jun and total JNK protein (a), northern blot analysis of CHOP and GRP78 (b), and TUNEL assay (c). The number of TUNEL-positive cells per field in the renal cortex was evaluated quantitatively (d). Data are expressed as means \pm S.E., and an asterisk indicates a statistically significant difference $(P<0.05)$. DAPI, $4^{\prime}-6-$ diamidino-2phenylindole staining

suppression of the IRE1 pathway by $3^{\prime}$-deoxyadenosine may be mediated, in part, by the activation of elF $2 \alpha$, whereas other mechanisms are also involved in the suppressive effect of $3^{\prime}$-deoxyadenosine. Indeed, we found that early phosphorylation of JNK by ER stress was inhibited by $3^{\prime}$-deoxyadenosine (Figure 4f), but not by salubrinal (Figure 6l).

In vivo suppression of ER stress-induced apoptosis by $3^{\prime}$-deoxyadenosine. We evaluated in vivo effects of 3'-deoxyadenosine on ER stress-induced apoptosis in mice. As shown in Figure 7a, activation of JNK was induced by tunicamycin in kidneys and livers, and it was suppressed by the administration with 3 '-deoxyadenosine. Northern blot analysis also showed that in vivo induction of CHOP and GRP78 was attenuated by $3^{\prime}$-deoxyadenosine (Figure $7 \mathrm{~b}$ ).

Tunicamycin induces renal tubular injury and apoptosis via ER stress. ${ }^{26}$ We evaluated an in vivo effect of $3^{\prime}$-deoxyadenosine on tunicamycin-induced apoptosis in renal tubules. Terminal deoxynucleotidyl transferase-mediated dUTP-biotin nick end labeling (TUNEL) exhibited numerous TUNELpositive apoptotic cells in kidneys of ER stress-induced mice, and it was substantially attenuated by the treatment with 3'-deoxyadenosine (Figure 7c). The number of TUNELpositive cells was significantly reduced by $3^{\prime}$-deoxyadenosine from $178 \pm 34$ cells/field to $78 \pm 11$ cells/field (means \pm S.E.; $P<0.05)$ (Figure 7d). Consistent with the in vitro data, these results provide in vivo evidence for the pro-survival potential of 3 '-deoxyadenosine to inhibit ER stress-induced apoptosis.

\section{Discussion}

ER stress-initiated apoptosis is regulated by three major branches of the UPR. We found that 3 -deoxyadenosine inhibits activation of the IRE1 pathway. Attenuation of ER stress per se was not the primary mechanism, because phosphorylation of PERK by ER stress was unaffected by $3^{\prime}$-deoxyadenosine. The fact that thapsigargin-induced downregulation of ER stress-responsive alkaline phosphatase, an exogenous indicator for ER stress, ${ }^{27}$ was not reversed by the treatment with 3 '-deoxyadenosine (Supplementary Figure S10) further supports this conclusion. Under ER stress conditions, the IRE1-ASK1-JNK pathway contributes to the induction of apoptosis. ${ }^{5}$ The suppression of this pro-apoptotic pathway may be one mechanism by which $3^{\prime}$-deoxyadenosine exerts its pro-survival effect.

In this report, we disclosed that $3^{\prime}$-deoxyadenosine induces phosphorylation of elF2 $\alpha$. Salubrinal mimicked the antiapoptotic effect of 3 -deoxyadenosine, and blockade of the PERK-elF2 $\alpha$ pathway rendered the cells susceptible to ER stress-induced apoptosis. These results indicate that translational suppression via elF $2 \alpha$ may play a role in the pro-survival effect of $3^{\prime}$-deoxyadenosine. Indeed, a recent report showed that $3^{\prime}$-deoxyadenosine strongly inhibited total protein synthesis. ${ }^{28}$ This phenomenon was observed in NIH3T3 cells treated by high concentrations of 3 -deoxyadenosine $(50-200 \mu \mathrm{M})$. However, we found that in NRK-52E cells, $3^{\prime}$-deoxyadenosine $(5 \mu \mathrm{g} / \mathrm{ml}$, approximately $20 \mu \mathrm{M})$ 
rather upregulated phosphorylation of p70S6 kinase that facilitates general translation. Using connexin 43 as an indicator, we also found that treatment with salubrinal for 24-48 $\mathrm{h}$ downregulated the level of this protein, whereas $3^{\prime}$-deoxyadenosine did not (our unpublished data). Although $3^{\prime}$-deoxyadenosine may have the potential to inhibit protein synthesis via interfering with transcriptional and translational events, ${ }^{28-30}$ further investigation will be required to determine the importance of translational suppression in the antiapoptotic effect of $3^{\prime}$-deoxyadenosine.

Currently, it is unclear how $3^{\prime}$-deoxyadenosine activates elF2 $\alpha$. One possibility is its suppressive effect on GADD34 that is involved in dephosphorylation of elF2 $\alpha .{ }^{7}$ As shown in this report, GADD34 was expressed in unstimulated cells, and it was suppressed by the treatment with $3^{\prime}$-deoxyadenosine. The downregulation of basal GADD34 might be a possible mechanism underlying phosphorylation of elF2 $\alpha$ by 3'-deoxyadenosine.

In general, phosphorylation of elF $2 \alpha$ causes induction of ATF4, resulting in expression of pro-apoptotic CHOP. The induction of ATF4 may be regulated at both transcriptional and translational level. ${ }^{24,25}$ Indeed, treatment with salubrinal resulted in expression of ATF4 and CHOP in NRK-52E cells. However, in contrast to salubrinal, $3^{\prime}$-deoxyadenosine did not induce and rather attenuated expression of ATF4 and $C H O P$. This unusual effect may, at least in part, contribute to the anti-apoptotic effect of $3^{\prime}$-deoxyadenosine. Previous reports suggested that $3^{\prime}$ deoxyadenosine inhibits transcriptional events through multiple mechanisms. ${ }^{29,30}$ It inhibits mRNA polyadenylation presumably by acting as a chain terminator. ${ }^{30}$ At high doses, $3^{\prime}$-deoxyadenosine inhibits incorporation of uridine into mRNA, but not into its precursor hnRNA, indicating that export, processing or stability of transcribed mRNA is affected. ${ }^{29}$ The suppression of ATF4 and $C H O P$ by $3^{\prime}$-deoxyadenosine, observed in this report, may be through the similar mechanisms on mRNAs. Of note, however, individual mRNAs have different susceptibility to $3^{\prime}$-deoxyadenosine. In our experimental setting, some mRNAs were unaffected by the treatment with $3^{\prime}$-deoxyadenosine. For example, the transcriptional level of luciferase driven by viral and housekeeping gene promoters was not depressed by $3^{\prime}$-deoxyadenosine. Although basal expression of $\beta$-actin mRNA was reduced by $3^{\prime}$-deoxyadenosine (our unpublished data), expression of $E F-1 \alpha$ and GAPDHmRNAs was unaffected by the treatment with this substance. Furthermore, we recently found that 3'-deoxyadenosine rather upregulated expression of monocyte chemoattractant protein 1 in differentiating preadipocytes (Supplementary Figure S11). These results are consistent with a recent report showing different sensitivity of different mRNAs to $3^{\prime}$-deoxyadenosine. ${ }^{31}$ Thus, the effect of $3^{\prime}$-deoxyadenosine on transcriptional events may not be so simple as was previously proposed.

Based on our current results, we propose a model underlying the anti-apoptotic effect of $3^{\prime}$-deoxyadenosine against ER stress (Figure 8a). 3'-Deoxyadenosine suppresses the IRE-JNK pro-apoptotic UPR at the proximal site. On the other hand, $3^{\prime}$-deoxyadenosine triggers phosphorylation of elF2 $\alpha$ and enhances ER stress-induced elF2 $\alpha$ activation, resulting in translational suppression and consequent attenuation of ER stress in the later phase. $3^{\prime}$-Deoxyadenosine also suppresses induction of ATF4 and GADD34, leading to sustained activation of elF2 $\alpha$. Although $3^{\prime}$-deoxyadenosine causes phosphorylation of elF $2 \alpha$, it does not induce and rather suppresses induction of the ATF4-CHOP pro-apoptotic pathway. It is contrastive to the effect of salubrinal that leads to induction of pro-apoptotic CHOP and GADD34. In addition, 3'-deoxyadenosine may attenuate ER stress via transcriptional suppression that preferentially targets particular mRNAs.

In the present report, we showed that the anti-apoptotic effect of $3^{\prime}$-deoxyadenosine is through adenosine receptordependent and -independent mechanisms, the former of which requires the $A 3$ adenosine receptor, but not $A 1 / A 2$ receptors. Contribution of the $\mathrm{A} 3$ receptor is consistent with a previous report showing that $3^{\prime}$-deoxyadenosine inhibited growth of tumor cells through the A3 receptor. ${ }^{10}$ In concert with this extracellular action, the transporter-dependent intracellular action of $3^{\prime}$-deoxyadenosine also plays a significant role for its effects against ER stress; for example, suppression of ATF4, GADD34 and CHOP. Regarding the activation of elF $2 \alpha$ by $3^{\prime}$-deoxyadenosine, however, the extracellular action and the intracellular action play distinct roles. We demonstrated that adenosine transporters, but not the $\mathrm{A} 3$ receptor, contributed to early phosphorylation of elF2 $\alpha$ by $3^{\prime}$-deoxyadenosine. In contrast, the A3 receptor was involved in the maintenance of phosphorylated elF2 $\alpha$ in the later phase. Based on our current results, we propose a hypothetical model shown in Figure 8b.

Individual UPR pathways possess both pro-apoptotic and anti-apoptotic properties. For example, the PERK pathway causes translational suppression that attenuates ER stress, whereas it also induces pro-apoptotic molecules including CHOP and GADD34. The IRE1 pathway triggers apoptosis via activation of ASK1 and JNK, but activation of IRE1 also induces ER chaperones and ERAD factors, both of which relief ER stress. ${ }^{32}$ In general, however, the PERK pathway is considered pro-survival, whereas the IRE1 pathway is regarded pro-apoptotic. ${ }^{3,4,33}$ From this viewpoint, the pharmacological of $3^{\prime}$-deoxyadenosine should be advantageous for blockade of ER stress-induced cell injury. Indeed, we demonstrated in this report that in vivo administration with $3^{\prime}$-deoxyadenosine suppressed ER stress-induced activation of the IRE1-JNK pathway, induction of $C H O P$ and consequent apoptosis in the kidney.

Taken together, the current results elucidated involvement of multiple targets for the anti-apoptotic action of 3 -deoxyadenosine against ER stress. This aberrant, differential and bidirectional regulation of the UPR may be advantageous for cell survival. Our results raise a possibility that $3^{\prime}$-deoxyadenosine could be useful for therapeutic intervention in an array of ER stress-related pathologies including infections, diabetes, malignant diseases, ischemic injury and neurodegenerative disorders.

\section{Materials and Methods}

Reagents. $3^{\prime}$-Deoxyadenosine, tunicamycin, thapsigargin, A23187, staurosporine, DTT, adenosine, MRS1523, NBTI, DPSPX, actinomycin D and Hoechst33258 were purchased from Sigma-Aldrich Japan. Cadmium chloride, ATP and ADP were obtained from Wako Pure Chemical (Osaka, Japan). Salubrinal was purchased from Tocris Bioscience (Ellisville, MO, USA), and human recombinant TNF- $\alpha$ was from R\&D Systems (Minneapolis, MN, USA). Cigarette smoke extract was prepared, as described previously. ${ }^{34}$ SubAB was kindly provided by Dr. James Paton (University of Adelaide). Throughout the study, 
a

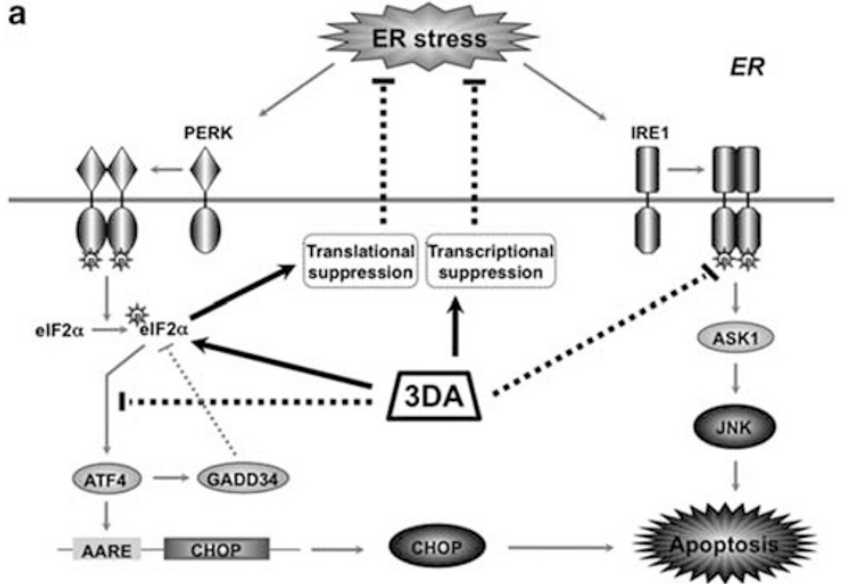

b 3DA

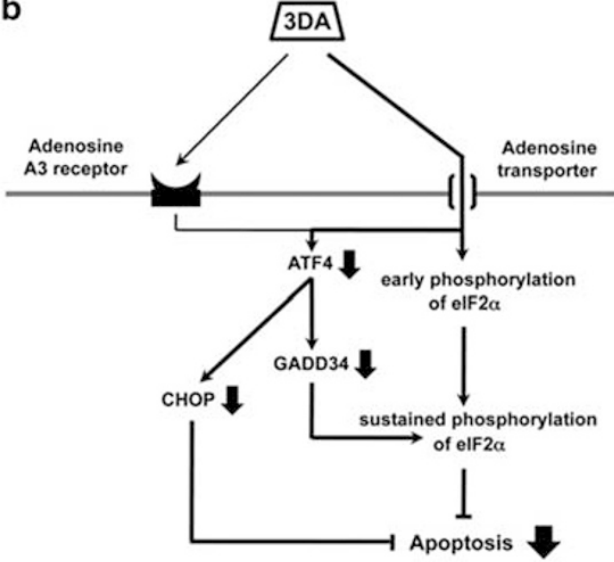

Figure 8 Molecular mechanisms involved in the suppression of ER stress-induced apoptosis by 3'-deoxyadenosine. (a) 3DA suppresses the IRE-JNK pro-apoptotic UPR at the proximal site. On the other hand, 3DA triggers phosphorylation of elF2 $\alpha$ and enhances ER stress-induced activation of elF2 $\alpha$, resulting in translational suppression and consequent attenuation of ER stress. 3DA also suppresses induction of ATF4 and GADD34, leading to sustained activation of elF2 $\alpha$. Although 3DA causes sustained phosphorylation of elF2 $\alpha$, it does not induce and rather suppresses induction of the ATF4-CHOP pro-apoptotic pathway. 3DA may attenuate ER stress via transcriptional suppression that targets particular mRNAs. (b) 3DA is transported into the cells through adenosine transporters and causes early phosphorylation of elF2 $\alpha$. 3DA suppresses expression of ATF4 and downstream GADD34 and CHOP by its intracellular action (major action) and extracellular action via the adenosine A3 receptor (minor action). These effects allow for sustained phosphorylation of elF2 $\alpha$ and blunted expression of pro-apoptotic genes, leading to attenuation of apoptosis

$3^{\prime}$-deoxyadenosine, tunicamycin and thapsigargin were used at concentrations $5 \mu \mathrm{g} / \mathrm{ml}, 2.5 \mu \mathrm{g} / \mathrm{ml}$ and $500 \mathrm{nM}$, respectively.

Cells. The rat renal tubular epithelial cell line NRK-52E and the human bronchial epithelial cell line BEAS-2B were purchased from American Type Culture Collection (Manassas, VA, USA), and the murine 3T3-L1 preadipocytes were obtained from Health Science Research Resources Bank (Osaka, Japan). The rat mesangial cell line SM43 was established and identified, as described previously. ${ }^{35}$ Cells were maintained in Dulbecco's modified Eagle's medium/Ham's F-12 (Gibco-BRL, Gaithersburg, MD, USA) supplemented with $5-10 \%$ fetal bovine serum (FBS). Assays were performed in the presence of $1 \%$ FBS.

Assessment of cell death. Cells were seeded in 24-well plates and treated with ER stress inducers for 48-72 $\mathrm{h}$. Both attached cells and detached cells were harvested separately and subjected to trypan blue analysis. The percentages of dead cells against total cells were evaluated in individual wells. Assays were performed in quadruplicate.

Hoechst staining. Cells were fixed in $2 \%$ formaldehyde for $10 \mathrm{~min}$, stained by Hoechst33258 $(10 \mu \mathrm{g} / \mathrm{ml})$ for $1 \mathrm{~h}$ and subjected to fluorescence microscopy.

Establishment of stable transfectants. NRK-52E cells were stably transfected with pUPRE-Luc or pERSE-Luc (provided by Dr. Laurie H Glimcher, Harvard Medical School) $)^{36}$ that introduces a luciferase gene under the control of UPRE or ERSE respectively, and NRK/UPRE-Luc cells and NRK/ERSE-Luc cells were established. NRK/PERK-DN cells were established by stable transfection with pcDNA3-hPERK.K621M (provided by Dr. Ronald C Wek, Indiana University School of Medicine). ${ }^{37}$ NRK/Neo cells transfected with pcDNA3.1 (Invitrogen, Carlsbad, CA, USA) were used as a control. SM/SV-SEAP cells were established by stable transfection of SM43 cells with pSEAP2-Control (BD Biosciences, Palo Alto, CA, USA) that introduces a SEAP gene under the control of the SV40 promoter.

Transient transfection. Using electroporation, NRK-52E cells were transiently transfected with pEF-1 $\alpha$-Luc, pCMV-Luc (provided by Dr. Takahiro Taira, University of Yamanashi) or pSV40-Luc (pGL3-Control; Promega, Madison, WI, USA), treated with $3^{\prime}$-deoxyadenosine and subjected to chemiluminescent assay. pEF- $1 \alpha$-Luc, pCMV-Luc and pSV40-Luc introduce a luciferase gene under the control of the EF- $1 \alpha$ promoter, the CMV promoter/enhancer and the SV40 promoter/enhancer, respectively. To evaluate cleavage of XBP1 mRNA, cells were transfected with pCAX-F-XBP1 $\triangle \mathrm{DBD}$-Luc (provided by Dr. Takao Iwawaki, RIKEN), ${ }^{38}$ treated with thapsigargin together with $3^{\prime}$-deoxyadenosine and subjected to analysis. pCHOP-Luc (provided by Dr. Pierre Fafournoux, INRA de Theix) that introduces a luciferase gene under the control of the CHOP gene promoter (originally designated as PCHOP $(-954 \pm 91)$-Luc) ${ }^{39}$ was also used to evaluate activity of the elF2 $\alpha$ pathway.

SEAP assay. Activity of SEAP was evaluated by a chemiluminescent method using Great EscAPe SEAP Detection Kit (BD Biosciences) according to the manufacturer's protocol. ${ }^{27}$

Luciferase assay. Activity of luciferase was evaluated by Luciferase Assay System (Promega) according to the manufacturer's protocol. ${ }^{27}$

Northern blot analysis. Total RNA was extracted by a single-step method, and northern blot analysis was performed as described before. ${ }^{40} \mathrm{cDNAs}$ for GRP78 (provided by Dr. Kazunori Imaizumi, University of Miyazaki). CHOP (provided by Dr. David Ron, New York University School of Medicine), PERK (provided by Dr. Ronald C Wek), GADD34 (provided by Dr. Takeshi Omasa, Osaka University), ATF4 (provided by Dr. David Ron), GRP94 (provided by Dr. Amy S Lee, University of South California), ORP150 (provided by Dr. Satoshi Ogawa, Kanazawa University), Edem1 (provided by Dr. Nobuko Hosokawa, Kyoto University), EF-1 $\alpha$ (provided by Dr. Jianxin Sun, New Jersey Medical School) and $\beta$-actin were used for preparation of radio-labeled probes. Expression of GAPDH was used as a loading control. Densitometric analysis was performed using Scion Image (Scion Corporation, Frederick, MO, USA).

Western blot analysis. Western blot analysis was performed as described before. ${ }^{33}$ Primary antibodies used were anti-caspase-3 antibody, anti-phospho elF2 $\alpha$ (Ser51) antibody, anti-c-Jun antibody and anti-phospho c-Jun (Ser63) antibody from Cell Signaling (Beverly, MA, USA); and anti-PERK antibody, antiphospho PERK (Thr981) antibody, anti-elF2 $\alpha$ antibody and anti-ATF4 (CREB-2) antibody from Santa Cruz Biotechnology (Santa Cruz, CA, USA). As a loading control, levels of $\beta$-actin and lamin B1 were evaluated using anti- $\beta$-actin antibody (Sigma-Aldrich Japan) and anti-lamin B1 antibody (Invitrogen). Phosphorylation of JNK was assessed by using PhosphoPlus SAPK/JNK (Thr183/Tyr185) Antibody Kit (Cell Signaling) following the protocol provided by the manufacturer. Nuclear protein was extracted using ProteoExtract Subcellular Proteome Extraction Kit (Merck $\mathrm{KGaA}$, Darmstadt, Germany).

RT-PCR. Reverse transcription was performed using Omniscript Reverse Transcriptase (Qiagen, Valencia, CA, USA). Splicing of XBP1 mRNA was examined 
using following primers: $5^{\prime}$-ACACGCTTGGGGATGAATGC-3' and $5^{\prime}$-CCATGGG AAGATGTTCTGGG-3' (Sigma-Aldrich Japan).

Animal experiments. C57BL/6 mice ( $20-25 \mathrm{~g}$ body weight; 12 male mice) were intraperitoneally injected (i.p.) with PBS or $3^{\prime}$-deoxyadenosine $(3 \mathrm{mg} / \mathrm{kg})$ on day 1, 2, 3 and 4. On day 2, mice were exposed to ER stress by single i.p. of tunicamycin ( $1.5 \mathrm{mg} / \mathrm{kg}$ ). After 3 days (day 5), kidneys were removed and processed for tissue sectioning for histopathological analysis and TUNEL assay. Renal cortex and liver were also used for western and northern blot analyses. 4'-6-Diamidino-2phenylindole (DAPI; Sigma-Aldrich Japan) was used for nuclear staining.

Histopathological analysis and TUNEL assay. Kidneys were fixed in $4 \%$ phosphate-buffered paraformaldehyde overnight at $4{ }^{\circ} \mathrm{C}$ and embedded in paraffin. Tissue sections were stained with hematoxylin and eosin. TUNEL assay was performed using Apoptosis Detection System, Fluorescein (Promega), as described previously. ${ }^{33}$ The number of TUNEL-positive cells per field (renal cortex) was counted, and the data were compared in different groups.

Statistical analysis. Data were expressed as means \pm S.E. Statistical analysis was performed using the non-parametric Mann-Whitney U-test to compare data in different groups. A $P$ value $<0.05$ was considered to indicate a statistically significant difference.

\section{Conflict of interest}

The authors declare no conflict of interest.

Acknowledgements. We thank Dr. Laurie H. Glimcher (Harvard Medical School), Dr. Ronald C. Wek (Indiana University School of Medicine), Dr. Takahiro Taira (University of Yamanashi), Dr. Takao Iwawaki (RIKEN), Dr. Takeshi Omasa (Osaka University), Dr. Pierre Fafournoux (INRA de Theix), Dr. Amy S Lee (University of South California), Dr. Satoshi Ogawa (Kanazawa University), Dr. Nobuko Hosokawa (Kyoto University), Dr. Jianxin Sun (New Jersey Medical School), Dr. Kazunori Imaizumi (University of Miyazaki) and Dr. David Ron (New York University School of Medicine) for providing us with plasmids. We also appreciate Dr. James Paton (University of Adelaide) for a kind gift of SubAB, and Miss Yukiko Kanayama and Mrs. Mikiko Yoda (University of Yamanashi) for technical assistance. This work was supported by Grant-in-Aids for Scientific Research from the Ministry of Education, Culture, Sports, Science and Technology, Japan (No.20390235) to M Kitamura, and in part by the Global COE Program and Smoking Research Foundation.

1. Aridor $M$, Balch WE. Integration of endoplasmic reticulum signaling in health and disease. Nat Med 1999; 5: 745-751.

2. Wu J, Kaufman RJ. From acute ER stress to physiological roles of the unfolded protein response. Cell Death Differ 2006; 13: 374-384.

3. Boyce M, Bryant KF, Jousse C, Long K, Harding HP, Scheuner D et al. A selective inhibitor of elF2 $\alpha$ dephosphorylation protects cells from ER stress. Science 2005; 307: 935-939.

4. Wiseman RL, Balch WE. A new pharmacology-drugging stressed folding pathways. Trends Mol Med 2005; 11: 347-350.

5. Kim R, Emi M, Tanabe K, Murakami S. Role of the unfolded protein response in cell death. Apoptosis 2006; 11: 5-13.

6. Ma Y, Brewer JW, Diehl JA, Hendershot LM. Two distinct stress signaling pathways converge upon the CHOP promoter during the mammalian unfolded protein response. $J$ Mol Biol 2002; 318: 1351-1365.

7. Novoa I, Zeng H, Harding HP, Ron D. Feedback inhibition of the unfolded protein response by GADD34-mediated dephosphorylation of elF2 $\alpha$. J Cell Biol 2001; 153: 1011-1022.

8. Cunningham KG, Manson W, Spring FS, Hutchinson SA. Cordycepin, a metabolic product isolated from cultures of Cordyceps militaris (Linn). Nature 1950; 166: 949.

9. Kaczka EA, Trenner NR, Arison B, Walker RW, Folkers K. Identification of cordycepin, a metabolite of Cordyceps militaris, as $3^{\prime}$-deoxyadenosine. Biochem Biophys Res Commun 1964; 14: 456-457.

10. Nakamura K, Yoshikawa N, Yamaguchi Y, Kagota S, Shinozuka K, Kunitomo M. Antitumor effect of cordycepin ( $3^{\prime}$-deoxyadenosine) on mouse melanoma and lung carcinoma cells involves adenosine A3 receptor stimulation. Anticancer Res 2006; 26: 43-47.

11. Chang W, Lim S, Song H, Song BW, Kim HJ, Cha MJ et al. Cordycepin inhibits vascular smooth muscle cell proliferation. Eur J Pharmacol 2008; 597: 64-69.

12. Lallas GC, Courtis N, Havredaki M. K562 cell sensitization to 5 -fluorouracil- or interferon- $\alpha$ induced apoptosis via cordycepin ( $3^{\prime}$-deoxyadenosine): fine control of cell apoptosis via poly(A) polymerase upregulation. Int J Biol Markers 2004; 19: 58-66.
13. Wu WC, Hsiao JR, Lian YY, Lin CY, Huang BM. The apoptotic effect of cordycepin on human OEC-M1 oral cancer cell line. Cancer Chemother Pharmacol 2007; 60: 103-111.

14. Chen LS, Stellrecht CM, Gandhi V. RNA-directed agent, cordycepin, induces cell death in multiple myeloma cells. Br J Haematol 2008; 140: 682-691.

15. Shi P, Huang Z, Tan X, Chen G. Proteomic detection of changes in protein expression induced by cordycepin in human hepatocellular carcinoma BEL-7402 cells. Methods Find Exp Clin Pharmacol 2008; 30: 347-353.

16. Erlinge D. Extracellular ATP: a growth factor for vascular smooth muscle cells. Gen Pharmacol 1998; 31: 1-8.

17. Kumar V, Sharma A. Adenosine: an endogenous modulator of innate immune system with therapeutic potential. Eur J Pharmacol 2009; 616: 7-15.

18. Czajkowski R, Barañska J. Cross-talk between the ATP and ADP nucleotide receptor signalling pathways in glioma C6 cells. Acta Biochim Pol 2002; 49: 877-889.

19. Paton AW, Beddoe T, Thorpe CM, Whisstock JC, Wilce MC, Rossjohn J et al. AB5 subtilase cytotoxin inactivates the endoplasmic reticulum chaperone BiP. Nature 2006; 443: 548-552.

20. Yoshida H, Matsui T, Hosokawa N, Kaufman RJ, Nagata K, Mori K. A time-dependent phase shift in the mammalian unfolded protein response. Dev Cell 2003; 4: 265-271.

21. Lee AS. The glucose-regulated proteins: stress induction and clinical applications. Trends Biochem Sci 2001; 26: 504-510.

22. Novoa I, Zhang $Y$, Zeng H, Jungreis R, Harding HP, Ron D. Stress-induced gene expression requires programmed recovery from translational repression. EMBO J 2003; 22: 1180-1187.

23. Harding HP, Novoa I, Zhang Y, Zeng H, Wek R, Schapira M et al. Regulated translation initiation controls stress-induced gene expression in mammalian cells. Mol Cell 2000; 6 : 1099-1108.

24. Armstrong JL, Flockhart R, Veal GJ, Lovat PE, Redfern CP. Regulation of endoplasmic reticulum stress-induced cell death by ATF4 in neuroectodermal tumor cells. J Biol Chem 2010; 285: 6091-6100.

25. Blais JD, Filipenko V, Bi M, Harding HP, Ron D, Koumenis $\mathrm{C}$ et al. Activating transcription factor 4 is translationally regulated by hypoxic stress. Mol Cell Biol 2004; 24: 7469-7482.

26. Nakagawa T, Zhu H, Morishima N, Li E, Xu J, Yankner BA et al. Caspase-12 mediates endoplasmic-reticulum-specific apoptosis and cytotoxicity by amyloid- $\beta$. Nature 2000; 403 : 98-103.

27. Hiramatsu N, Kasai A, Hayakawa K, Yao J, Kitamura M. Real-time detection and continuous monitoring of ER stress in vitro and in vivo by ES-TRAP: evidence for systemic, transient ER stress during endotoxemia. Nucleic Acids Res 2006; 34: e93.

28. Wong YY, Moon A, Duffin R, Barthet-Barateig A, Meijer HA, Clemens MJ et al. Cordycepin inhibits protein synthesis and cell adhesion through effects on signal transduction. J Biol Chem 2010; 285: 2610-2621.

29. Penman S, Rosbash M, Penman M. Messenger and heterogeneous nuclear RNA in HeLa cells: differential inhibition by cordycepin. Proc Natl Acad Sci USA 1970; 67: 1878-1885

30. Müller WE, Seibert G, Beyer R, Breter HJ, Maidhof A, Zahn RK. Effect of cordycepin on nucleic acid metabolism in L5178Y cells and on nucleic acid-synthesizing enzyme systems. Cancer Res 1977; 37: 3824-3833.

31. Wong YY, Moon A, Duffin R, Barthet-Barateig A, Meijer HA, Clemens MJ et al. Cordycepin inhibits protein synthesis and cell adhesion through effects on signal transduction. J Biol Chem 2010; 285: 2610-2621.

32. Rutkowski DT, Kaufman RJ. That which does not kill me makes me stronger: adapting to chronic ER stress. Trends Biochem Sci 2007; 32: 469-476.

33. Yokouchi M, Hiramatsu N, Hayakawa K, Kasai A, Takano Y, Yao J et al. Atypical, bidirectional regulation of cadmium-induced apoptosis via distinct signaling of unfolded protein response. Cell Death Differ 2007; 14: 1467-1474.

34. Tagawa Y, Hiramatsu N, Kasai A, Hayakawa K, Okamura M, Yao J et al. Induction of apoptosis by cigarette smoke via ROS-dependent endoplasmic reticulum stress and CCAAT/enhancer-binding protein-homologous protein (CHOP). Free Radic Biol Med 2008; 45: 50-59.

35. Kitamura M, Taylor S, Unwin R, Burton S, Shimizu F, Fine LG. Gene transfer into the rat renal glomerulus via a mesangial cell vector: site-specific delivery, in situ amplification, and sustained expression of an exogenous gene in vivo. J Clin Invest 1994; 94: 497-505.

36. Lee AH, Iwakoshi NN, Glimcher LH. XBP-1 regulates a subset of endoplasmic reticulum resident chaperone genes in the unfolded protein response. Mol Cell Biol 2003; 23: 7448-7459.

37. Fernandez J, Yaman I, Sarnow P, Snider MD, Hatzoglou M. Regulation of internal ribosomal entry site-mediated translation by phosphorylation of the translation initiation factor elF2 $\alpha$. J Biol Chem 2002; 277: 19198-19205.

38. Iwawaki T, Akai R. Analysis of the XBP1 splicing mechanism using endoplasmic reticulum stress-indicators. Biochem Biophys Res Commun 2006; 350: 709-715.

39. Bruhat A, Jousse C, Carraro V, Reimold AM, Ferrara M, Fafournoux P. Amino acids control mammalian gene transcription: activating transcription factor 2 is essential for the amino acid responsiveness of the CHOP promoter. Mol Cell Biol 2000; 19: 7192-7204.

40. Kitamura M, Suto T, Yokoo T, Shimizu F, Fine LG. Transforming growth factor- $\beta 1$ is the predominant paracrine inhibitor of macrophage cytokine synthesis produced by glomerular mesangial cells. J Immunol 1996; 156: 2964-2971. 